\title{
Flow field designs developed by comprehensive CFD model decrease system costs of vanadium redox-flow batteries
}

\author{
E. Prumbohm ${ }^{1,2}$ (D) M. Becker ${ }^{1,2}$ (D) $\cdot$ S. Flaischlen ${ }^{1,2}$ (D) $\cdot$ G. D. Wehinger ${ }^{1,2}$ (D) $\cdot$ T. Turek $^{1,2}$ (D)
}

Received: 15 January 2021 / Accepted: 19 April 2021 / Published online: 14 June 2021

(C) The Author(s) 2021

\begin{abstract}
Different flow field designs are known for vanadium redox-flow batteries (VFB). The best possible design to fulfil a variety of target parameters depends on the boundary conditions. Starting from an exemplary interdigitated flow field design, its channel and land dimensions are varied to investigate the impact on pressure drop, channel volume, flow uniformity and limiting current density. To find a desirable compromise between these several partly contrary requirements, the total costs of the VFB system are evaluated in dependence of the flow field's dimensions. The total costs are composed of the electrolyte, production and component costs. For those, the production technique (injection moulding or milling), the pump and nominal power density as well as depth of discharge are determined. Finally, flow field designs are achieved, which lead to significantly reduced costs. The presented method is applicable for the design process of other flow fields and types of flow batteries.
\end{abstract}

Keywords Computational fluid dynamics $\cdot$ Redox-flow batteries $\cdot$ Flow field designs $\cdot$ Battery costs

\section{Introduction}

Redox-flow batteries (RFB) are a promising large scale energy storage technology [1]. Great advantages of RFBs are their independent scalability and energy as well as their intrinsic safety. Vanadium redox-flow batteries (VFB), which are available in the $\mathrm{kW}$ to $\mathrm{MW}$ range, have already been intensively studied [2-4]. Currently there is a special focus on the transferability of the results from lab to operational scale [5].

\section{Highlights}

- Half-cell model of vanadium redox-flow battery consisting of interdigitated flow field and electrode

- Flow field design study with varied geometric flow field parameters by computational fluid dynamics simulations

- Pressure drop, flow distribution, mass transport and total costs as target parameters

\section{E. Prumbohm}

prumbohm@icvt.tu-clausthal.de

1 Institute of Chemical and Electrochemical Process Engineering, Clausthal University of Technology, Leibnizstraße 17, 38678 Clausthal-Zellerfeld, Germany

2 Research Center for Energy Storage Technologies, Clausthal University of Technology, Am Stollen 19A, 38640 Goslar, Germany
The VFB performance is affected by numerous influences. These include the used materials, the applied designs and the operational parameters of the VFB [6]. The additional insertion of flow fields at the cell level in the bipolar plate or the electrode allows to reduce pressure losses and to improve flow characteristics. For VFB mainly serpentine and interdigitated flow field designs (IFF) were applied by experimental and simulation based studies. Thereby, typically the distance between the channels, called land width, is as large as the channel width or twice as large as it [7]. Depending on the flow field design, stagnation zones can be reduced, local mass transport is increased and a more uniform distribution of electrolyte flow, current density and potential is accessible [7-9]. For large cell sizes it was shown that in particular IFF designs lead to a reduced pump power and a high uniformity in comparison to serpentine design [8]. A hierarchically structured IFF is characterized by its additional secondary branches. In comparison to an IFF with only primary branches, those structures can encourage a further reduction of the required pump power and an improvement of the voltage efficiency [10]. Another investigated possibility is the introduction of ramps within the IFF channels, which lead to lower pressure differences, too [11]. Nevertheless, it has to be emphasised that the best flow field structure depends strongly on the boundary conditions such as electrode and electrolyte properties as well as the operational parameters [12]. Therefore, efficient flow 
field designs have to be adjusted to these boundary conditions. For instance the observation of the pumping-corrected voltage efficiency in dependence of the channel and land dimensions as well as the flow rate allows to find favourable flow field designs [9]. Furthermore, it was shown that also topological approaches can be used for the optimisation of flow field designs [13]. By means of optimisation, the local electrode porosity was adjusted, since this also allows to improve the flow uniformity and efficiency of VFB [14]. Thereby, the aim is to adapt the properties of the electrode even better to the conditions in the RFB [15]. In this context other approaches are for instance, the variation of the electrode porosity [16] and the development of electrodes, which are structured at the micron- as well as the nano-scale [17].

Computational fluid dynamics (CFD) simulations are applicable for optimisation studies [18]. It is possible to describe the VFB's electrode in CFD models fibre dissolved or as porous media. The electrode structure and the associated material properties depend strongly on the electrode material and characteristics. By optical measurements it was shown that for instance in a carbon felt electrode, the flow distribution is not completely homogeneous [19]. For the description of the permeability of the electrode, either experimental data in dependence of the electrode's compression rate or model-based approaches can be applied [20]. The transport phenomena in RFB are assessable by the application of correlation equations for the mass transfer coefficient. Several correlation equations exist for fibrous carbon electrodes, which differ in the resulting order of magnitude for the mass transfer coefficient $[21,22]$.
In this study, a cell design with an IFF in the industrial scale with an active area of around $0.06 \mathrm{~m}^{2}$ is investigated. The relations between the flow field parameters and the VFB's system parameters are presented for all channel dimensions in the observed parameter range. The considered system variables are the pressure drop, the volume of the flow field channels, the uniformity of the velocity in the electrode and the limiting current density. Subsequently, the obtained results are transferred to the system costs of the VFB. Based on the observed parameter range for the set boundary conditions, most beneficial dimensions of IFF designs are outlined.

\section{Methods}

The general setup of a VFB cell is sketched in Fig. 1. The shown main components of the VFB are the monopolar respective bipolar plates, the electrodes and the membrane as well as the electrolyte inlet and outlet for the negative $\left(\mathrm{V}^{2+}\right.$ and $\left.\mathrm{V}^{3+}\right)$ and the positive electrolyte $\left(\mathrm{VO}^{2+}\right.$ and $\mathrm{VO}_{2}{ }^{+}$, which are named by their oxidation numbers $\mathrm{V}^{4+}$ and $\mathrm{V}^{5+}$ in the following). In a VFB system, which is defined by its nominal power and capacity, several cells are combined to a stack. The electrolyte, which is stored in the tanks, is pumped during the operation through the stack respectively cells. To evaluate the performance of the VFB system, the achievable nominal power density and depth of discharge are characteristic values as well as its coulomb and energy efficiency. The results are obtained by a CFD model, which describes one VFB half cell.

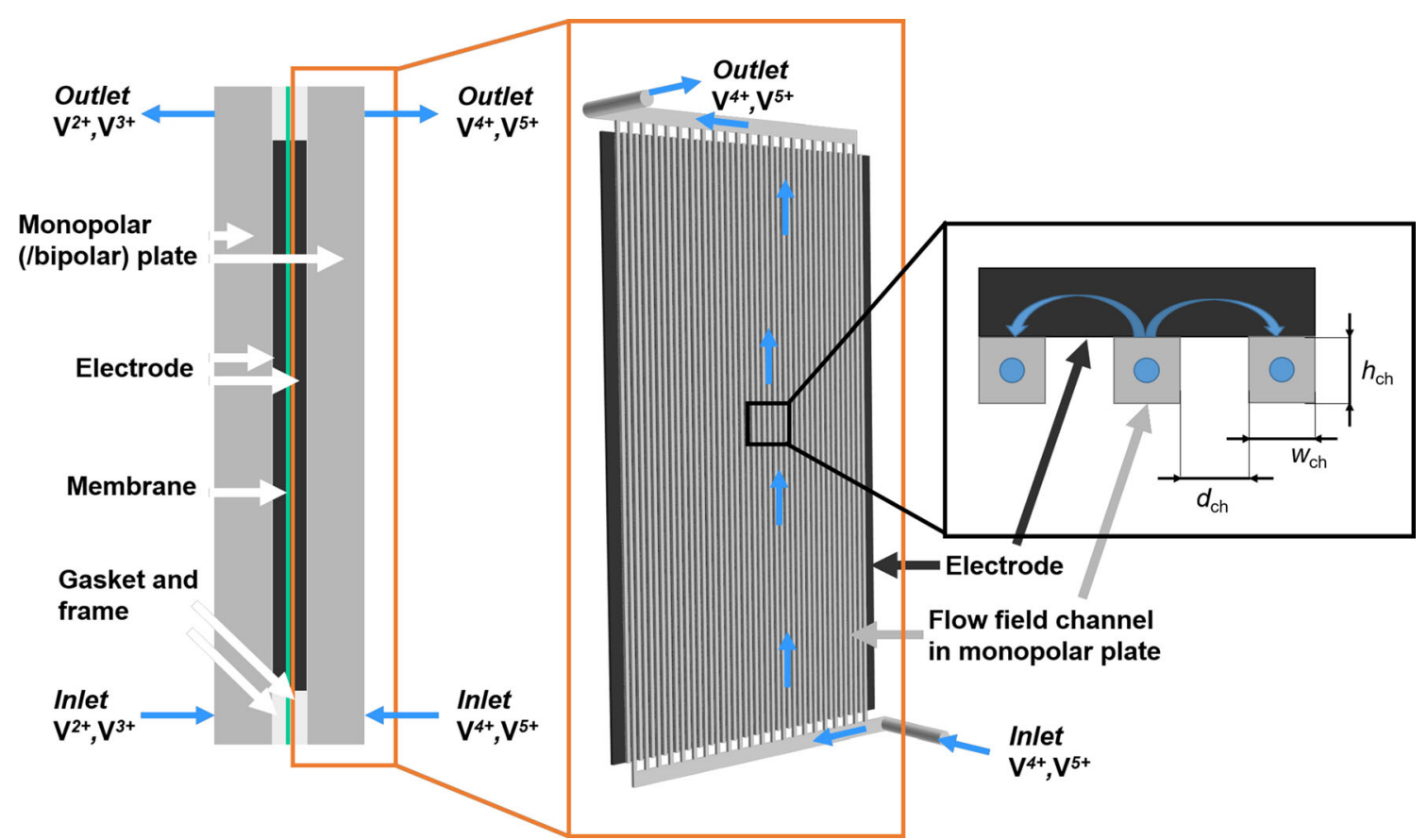

Fig. 1 VFB setup consisting of the monopolar respectively bipolar plate, the electrodes and the membrane with a closer look at the positive half cell, which is described with the CFD model 


\section{CFD model}

In the model, the half cell consists of the electrode region and the flow field region. The flow field region is composed of the supply channels and the flown through channels of an IFF design. Concerning the kinetics, the reaction rate of the positive electrolyte (PE) is higher than the one of the negative electrolyte [23]. Therefore, mass transport limitation, which can be reduced by improved flow field designs, have a larger impact on the PE side. In the following, the half cell of the PE is examined.

In this study different flow field designs for VFB are evaluated. Out of the requirements, which have to be met by flow field designs, the effect of the variation of the flow field channel and land dimensions on the four major demands of Table 1 is analysed. Those are called system parameters.

\section{Model setup and mesh}

For this study, the model is set up in the commercial engineering software package Simcenter STAR-CCM+ Version 15.06.007-R8 from Siemens Digital Industries Software. For the CFD model, the fluid volume is generated as CAD designs, which geometries are sketched within the software. For all investigated designs, the inlet and outlet position as well as geometric dimensions of the electrode are fixed. The geometric input parameters of this study are the channel width $w_{\mathrm{ch}}$ and height $h_{\mathrm{ch}}$ as well as the land width $d_{\mathrm{ch}}$, see the right side of Fig. 1 and Table 2. The pressure drop is supposed to be below 0.5 bar, which is necessary to avoid pressure equipment directive (PED) restrictions. Thereby, all designs with a pressure drop above this level are marked.

Additionally, design parameters are formulated in dependence of the input parameters. Those design parameters for the geometry sketch are the total number of channels, the length and the depth of the supply channels and the position of the first channel along the supply channel, see Fig. 2. Furthermore, electrode areas are considered, in which no channels are allowed to be placed during the variation of the channel and land dimensions. This is done to avoid that the electrode might dent into the channels at the electrode outer edges.
For the CFD model, a conformal polyhedral part-based mesh with three prism layers is generated, for which also the surface remesher, automatic surface repair and volume mesher are used within Simcenter STAR-CCM+. The settings of the mesh include several characteristic values, which are partly dependent on the definition of the base size in Simcenter STAR-CCM+, which is set to $0.75 \mathrm{~mm}$. For instance, the surface edge length is defined generally by the target surface size of $50 \%$ relative to the value of the base size. Additionally, the minimum surface size of $20 \%$ of the base size is included. The total number of computational cells for the exemplary design is approx. 10 million. For this design, the extrapolated relative error (ERE) is estimated by Richardson extrapolation for the pressure drop, the velocity uniformity and the limiting current density after [24], see the Appendix for further information. The deviation of the results for the chosen mesh in comparison to an assumed mesh with an infinite small mesh size is very small respectively negligibly small $\left(\mathrm{ERE}_{p}=3.3 \%\right.$; $\mathrm{ERE}_{\psi}=0.1 \%$ and $\mathrm{ERE}_{i L}=0.2 \%$ ). Furthermore, the differences between the simulation results for the different flow field designs in the observed parameter range are to a large extent significantly higher than the estimated error due to the mesh, see Results and Discussion section. Therefore, as the selected mesh parameters lead to reasonable mesh calculation times and simulation results, they are kept constant throughout this design study. Still, this leaves some potential for adjustments in the future, as even further adaption of the mesh settings to the geometric parameters of each design might be beneficial. We have observed that mostly less than 300 iterations are sufficient to monitor no significant changes of the pressure drop between cell inlet and outlet and the average velocity at the outlet between the iterations. Yet, to guarantee a completely converged solution for all possible designs, we set the stopping criteria to 600 iterations and monitored the pressure drop and average velocity, respectively.

\section{Governing equations}

The model is three dimensional, steady-state with turbulent, incompressible flow. The continuity equation for the fluid flow is given in Eq. (1) with the physical velocity vector $\mathbf{v}$. Furthermore, the momentum equation of the fluid flow is

Table 1 System parameter and their purpose for the flow field designing process

\begin{tabular}{ll}
\hline System parameter & Purpose \\
\hline Low pressure drop between cell in- and outlet & Reducing operational costs and avoiding the need of application of PED \\
Low volume of the flow field channels & Enabling a short and cheap production \\
High flow uniformity & Reducing losses of active membrane area \\
High limiting current density & Improving mass transport and thereby to reduce overpotentials \\
\hline
\end{tabular}


Table 2 Input parameters and their explained values

\begin{tabular}{lll}
\hline Input parameter & Value & Explanation \\
\hline Channel width & Minimum: $1 \mathrm{~mm}$ & $>$ Electrode might dent due to wider channels \\
& Maximum: $5 \mathrm{~mm}$ & \\
& Step size: $1 \mathrm{~mm}$ & \\
Channel height & Minimum: $1 \mathrm{~mm}$ & \\
& Maximum: $3 \mathrm{~mm}$ & \\
& Step size: $1 \mathrm{~mm}$ & \\
Land width & Minimum: $2 \mathrm{~mm}$ & \\
& Maximum: $50 \mathrm{~mm}$ & \\
& Step size: $4 \mathrm{~mm}$ & \\
\hline
\end{tabular}

shown in Eq. (2) including the stress tensor T. The electrode is defined by the porous media model. For the fluid flow through the porous media, the continuity equation is given in Eq. (3). In the momentum equation with the pressure $p$ and the stress tensor $\mathbf{T}$ of Eq. (4), the tensor for the porous viscous resistance $\mathbf{P}_{\mathrm{V}}$ and the porous inertial resistance $\mathbf{P}_{\mathrm{i}}$ are included. The vector of the superficial velocity $\mathbf{v}_{\mathbf{s}}$ results from the porosity $\varepsilon$ and the physical velocity $\mathbf{v}$ (Eq. (5)). The electrode's permeability $K$ is included by Eq. (6) in the porous viscous resistance $\mathbf{P}_{\mathrm{v}}$ and by the Forchheimer constant $\beta_{\mathrm{F}}$ of Eq. (7) in the porous inertial resistance $\mathbf{P}_{\mathrm{i}}$. Thereby, the Forchheimer constant is defined in Eq. (8) in dependence of the electrode's tortuosity $\tau$ and porosity $\varepsilon$ (Eqs. (9) and (10)), after [25, 26]. Additionally, they change in dependence of the state of charge (SoC). The SoC dependence of the density $\rho_{\mathrm{PE}}$ is given by Eq. (11) and the dynamic viscosity $\mu_{\mathrm{PE}}$ in Eq. (12) after [21]. For

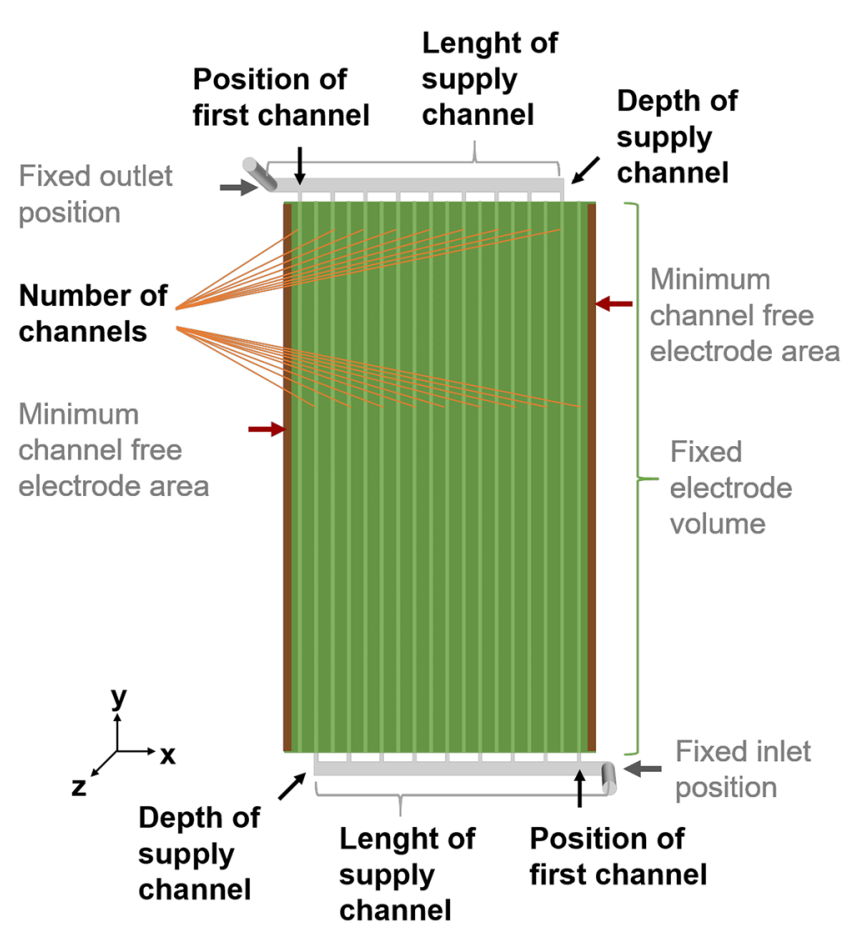

Fig. 2 Geometry setup with fixed and flow field dependent design parameters the mo-del, a one electrode layer design with a compressed carbon felt electrode is chosen. Its material data such as its porosity $\varepsilon$ and permeability $K$ correspond to the characteristics of a SGL Sigracell@ GFD 2.5 EA carbon felt electrode (SGL Group, Germany) with a compression rate of $20 \%$, see Table 3.

$\nabla \cdot\left(\rho_{\mathrm{PE}} \mathbf{v}\right)=0$

$\nabla \cdot\left(\rho_{\mathrm{PE}} \mathbf{v v}\right)=\nabla \mathbf{T}$

$\nabla \cdot\left(\varepsilon \rho_{\mathrm{PE}} \mathbf{V}\right)=0$

$\nabla \cdot\left(\varepsilon \rho_{\mathrm{PE}} \mathbf{V v}\right)=-\varepsilon \nabla p-\nabla \cdot(\varepsilon \mathbf{T})-\varepsilon \mathbf{P}_{\mathrm{v}} \mathbf{v}_{s}-\varepsilon \mathbf{P}_{\mathrm{i}}\left|\mathbf{v}_{S}\right| \mathbf{v}_{S}$

$\mathbf{v}_{s}=\varepsilon \mathbf{v}$

$\mathbf{P}_{\mathbf{v}}=\frac{\mu_{\mathrm{PE}}}{K}$

$\mathbf{P}_{\mathbf{i}}=\varepsilon \rho_{\mathrm{PE}} \beta_{\mathrm{F}}$

$\beta_{\mathrm{F}}=2,88 \cdot 10^{-6} \frac{\tau}{\varepsilon K}$

$\tau=\frac{1}{\varepsilon^{1 / 2}}$

$\varepsilon=1-\frac{1-\varepsilon_{0}}{V_{\mathrm{C}} / V_{0}}$

$\rho_{\mathrm{PE}}(\mathrm{SoC})=(1330+20 \cdot \mathrm{SoC}) \frac{\mathrm{kg}}{\mathrm{m}^{3}}$

$\mu_{\mathrm{PE}}(\mathrm{SoC})=(4.53-0.76 \cdot \mathrm{SoC}) \mathrm{mPa} \mathrm{s}$

The fluid is defined as a multi-component liquid. Its mass fractions are corresponding to the vanadium electrolyte solution, which consists of the vanadium species, water, sulphate and others including phosphoric acid and further additives, from GfE (Gesellschaft für Elektrometallurgie mbH, Germany) after [27]. The total molar vanadium concentration is around $1.6 \mathrm{kmol} / \mathrm{m}^{3}$ with $4 \mathrm{kmol} / \mathrm{m}^{3}$ sulphate. At the velocity inlet, the SoC and the velocity are specified. Generally, mass transport limitations occur for charging at a high SoC. Nevertheless, for this CFD model a quite low value of $20 \%$ for 
the $\mathrm{SoC}$ is chosen, as this allows to observe the effect of the flow field design on the local vanadium concentration. The distribution of the vanadium concentration thereby depends on the selected mass transport correlation, which is explained further on. Assuming an average current density of $200 \mathrm{~mA} /$ $\mathrm{cm}^{2}$ and a concentration gradient of $10 \%$ between cell inlet and cell outlet, the inlet velocity is calculated by applying Faraday's law. The cell outlet is set as pressure outlet with atmospheric pressure. In this study, the case of charging is investigated in the CFD model. In Eq. (13), the species transport in the electrode includes for the mass fraction $Y_{i}$ the effect of the diffusion and the source term $S_{Y_{\mathrm{i}}}$, which is given in Eq. (16). The mass fraction $Y_{i}$ results from the molar concentration $c_{i}$ of the species $i$ (Eq. (14)). The source term $S$ of the vanadium species is defined after [28] and is adjusted for this model by the molecular weight $W_{i}$ (Eq. (15)). Furthermore, the definition of the species source term follows the assumption of [29]. According to the explanations given there, the application of the volumetric limiting current density $i_{\lim }$ allows to evaluate the electrolyte's availability under mass transport limitation (Eq. (17)). The limiting current density depends on the mass transfer coefficient $k_{\mathrm{m}}$, which is determined by the mass transport correlation equation (Eq. (18)). Within this study, the correlation equations after [21] is applied (Eq. (19)).

$$
\begin{aligned}
& \nabla \cdot\left(\rho_{\mathrm{PE}} \mathbf{v} Y_{i}\right)=\nabla \cdot\left[\frac{\varepsilon}{\tau} \rho D_{i} \nabla Y_{i}+\frac{\mu_{t}}{\sigma_{t}} \nabla Y_{i}\right]+S_{Y_{i}} \\
& Y_{i}=\frac{c_{i} \cdot W_{i}}{\rho_{m}} \\
& S_{Y_{i}}=S \cdot W_{i} \\
& S=-a \cdot k_{\mathrm{m}} \cdot c_{\mathrm{V}} \\
& i_{\mathrm{lim}}=z \cdot a \cdot k_{\mathrm{m}} \cdot c_{\mathrm{V}} \cdot F \\
& S h=k_{\mathrm{m}} \cdot \frac{d_{\mathrm{f}}}{D_{i}} \\
& S h=0.07 \operatorname{Re}^{0.66} S c^{0.45}
\end{aligned}
$$

The flow distribution in the electrode volume is evaluated by the uniformity index $\Psi_{\text {uni }}$ of Eq. (20), which is defined within the software package Simcenter STAR-CCM+ after [30, 31]. For the calculation of the uniformity index $\Psi_{\text {uni }}$, the local velocity magnitude $v_{\mathrm{c}}$ is compared to the overall volume average of the velocity magnitude $\bar{v}$ under consideration of the cell volume $V_{\mathrm{c}}$.

$\psi_{\text {uni }}=1-\frac{\sum_{\mathrm{c}}\left|\nu_{\mathrm{c}}-\bar{v}\right| V_{\mathrm{c}}}{2|\bar{v}| \sum_{\mathrm{c}} V_{\mathrm{c}}}$

\section{Cost model}

Based on the previously described CFD model, the total costs are estimated for a VFB system in the MW-range. The system's characteristic values for the nominal power $P_{\mathrm{N}}$ and nominal capacity $Q_{\mathrm{N}}$ are given in Table 4 . The beforehand named four requirements are taken into account in the estimation of the total costs as follows:

- Low pressure drop $\rightarrow$ low pumping power

- Low volume of flow field channels $\rightarrow$ low specific production costs

- High flow uniformity $\rightarrow$ high nominal power density and high depth of discharge (DoD)

- High limiting current density $\rightarrow$ high nominal power density and high DoD

\section{VFB system costs}

The resulting interrelations are explained further on in detail. The introduced total costs of the VFB system include the costs for the electrolyte $C_{\text {electrolyte }}$ as well as the specific costs for the cell respectively stack components $c_{\text {comp }}$ and for the production $c_{\text {prod }}$ (Eq. (21)). The costs of the electrolyte $C_{\text {electrolyte }}$ depend on the given nominal capacity $Q_{\mathrm{N}}$ and an additional operational term to cover the needed pump power $P_{\text {Pump. }}$. Moreover, the electrolyte costs $C_{\text {electrolyte }}$ are determined by the DoD and the specific electrolyte costs $c_{\text {electrolyte, }}$ which are assumed to be $102 € / \mathrm{kWh}$ after [34, 35], see Eqs. (22) and (23). The needed pump power $P_{\text {Pump }}$ results from the beforehand observed pressure drop $\Delta p$ between cell inlet and cell outlet. Furthermore, it depends on the pump efficiency $\eta_{\text {Pump }}$, the total number of cells $n_{\mathrm{c}}$ and the volume flow rate, which is defined by the velocity at the cell inlet $v_{\text {in }}$ and the inlet area $A_{\text {in }}$. As the pressure drop has to be overcome for both half cells, for

Table 3 Model constants for fluid and electrode

\begin{tabular}{lllll}
\hline Parameter & Name & Value & Unit & Reference \\
\hline$v_{\text {in }}$ & Velocity magnitude at the inlet & 0.162 & $\mathrm{~m} / \mathrm{s}$ & Chosen \\
$d_{\mathrm{f}}$ & Carbon felt fibre diameter & 10 & $\mu \mathrm{m}$ & {$[32]$} \\
$a$ & Specific surface area & 60,000 & $\mathrm{~m}^{2} / \mathrm{m}^{3}$ & $\mathrm{~m}^{2}$ \\
$K$ & Permeability & $1 \cdot 10^{-10}$ & - & Estimated \\
$\varepsilon_{0}$ & Open porosity & 0.94 & {$[33]$} \\
$D_{\mathrm{V}}{ }^{4+}$ & $\mathrm{V}^{4+}$ diffusion coefficient & $1.6 \cdot 10^{-10}$ & $\mathrm{~m}^{2} / \mathrm{s}$ & {$[21]$} \\
\hline
\end{tabular}


reasons of simplicity the factor 2 is included in Eq. (24). Still, this assumption neglects the fact that the pressure drop differs depending on the half cell due to the electrolyte's properties. The cell area is equal to the electrode area $A_{\text {electrode }}$ and therefore, the relation between the total number of cells $n_{\mathrm{c}}$ and the total area of all cells $A_{\text {total }}$ is given by Eq. (25). In this context, the total area $A_{\text {total }}$ is not only defined by the ratio of set nominal power $P_{\mathrm{N}}$ to the nominal power density $p_{\mathrm{N}}$, but again an additional term is included in Eq. (25) to consider the needed pump power $P_{\text {Pump. }}$.

$$
\begin{aligned}
& C_{\text {total }}=C_{\text {electrolyte }}+\left(c_{\text {comp }}+c_{\text {prod }}\right) \cdot A_{\text {total }} \\
& C_{\text {electrolyte }}=c_{\text {electrolyte }} \cdot \frac{Q^{\prime}}{\mathrm{DoD}} \\
& Q^{\prime}=Q_{\mathrm{N}} \cdot\left(1+\frac{P_{\text {Pump }}}{P_{\mathrm{N}}}\right) \\
& P_{\text {Pump }}=\Delta p \cdot \eta_{\text {pump }} \cdot n_{\mathrm{c}} \cdot v_{\text {in }} \cdot A_{\text {in }} \cdot 2 \\
& A_{\text {total }}=A_{\text {electrode }} \cdot n_{\mathrm{c}}=\frac{P_{\mathrm{N}}+P_{\text {Pump }}}{p_{\mathrm{N}}}
\end{aligned}
$$

\section{Nominal power and depth of discharge}

The nominal power density $p_{\mathrm{N}}$ as well as the DoD are linked to the limiting current density $i_{\lim }, 20 \%$ and the uniformity index $\psi_{\text {uni. }}$. The listed three calculation parts are needed to gain the nominal power density and the DoD from the limiting current density and the uniformity index.

Part I: Description of charge/discharge behaviour based on limiting current density and uniformity index

Table 4 Model constants for the VFB cell and system

\begin{tabular}{llll}
\hline Parameter & Name & Value & Unit \\
\hline$A_{\text {in }}$ & Area of the inlet & 0.5027 & $\mathrm{~cm}^{2}$ \\
$\eta_{\text {pump }}$ & Pump efficiency & 80 & $\%$ \\
$v_{\text {feed,EM }}$ & Feed rate EM & 2 & $\mathrm{~m} / \mathrm{min}$ \\
$c_{\mathrm{EM}}$ & Specific machine costs for EM & 100 & $€ / \mathrm{h}$ \\
$c_{\text {wear,EM }}$ & Specific costs for cutter wear & 0.1 & $€ / \mathrm{m}$ \\
$P_{\mathrm{N}}$ & Nominal power & 1 & $\mathrm{MW}$ \\
$Q_{\mathrm{N}}$ & Nominal capacity & 6 & $\mathrm{MWh}$ \\
$R_{0}$ & Specific cell resistance & 1 & $\Omega \mathrm{cm}^{2}$ \\
$E_{0}$ & Equilibrium voltage & 1.42 & $\mathrm{~V}$ \\
$U_{\text {min }}$ & Minimum voltage & 0.9 & $\mathrm{~V}$ \\
$U_{\text {max }}$ & Maximum voltage & 1.65 & $\mathrm{~V}$ \\
$\eta_{\mathrm{CE}}$ & Coulomb efficiency & 95 & $\%$ \\
$\eta_{\mathrm{EE}}$ & Energy efficiency & 80 & $\%$ \\
\hline
\end{tabular}

Part II: Calculation of discharge voltage for a set voltage efficiency

Part III: Identification and calculation of the nominal power density and DoD by using the discharge voltage from part II to find the corresponding discharge voltage in the results of part I

For part I, the dependences for charging and discharging between cell voltage $U_{\text {cell }}$, current $i$ and power density $p$ are calculated for a SoC of $50 \%$. The limiting current density $i$ lim,20\% from the CFD simulations is transferred to the desired limiting current density $i_{\text {lim }}$ for a SoC of $50 \%$ by Eqs. (26) and (27). Based on this adjusted limiting current density, the cell voltage $U_{\text {cell }}$ is calculated after Eq. (28) for charging and after Eq. (29) for discharging in dependence of the open circuit voltage $U_{\mathrm{OCV}}$. Thereby, the dependence of the open circuit voltage $U_{\mathrm{OCV}}$ on the $\mathrm{SoC}$ is given in Eq. (30). Furthermore, Eqs. (28) and (29) include the overpotentials due to ohmic losses by the specific cell resistance $R_{0}$ and due to mass transport limitations. From the cell voltage $U_{\text {cell }}$ and the current density $i$, the power density $p$ for charging and discharging results according to Eqs. (31) and (32).

$$
\begin{aligned}
& i_{\text {lim,ch. }}=-i_{\text {lim }, 20 \%} \cdot \frac{1-\mathrm{SoC}}{(100 \%-20 \%)} \\
& i_{\text {lim,dis. }}=i_{\text {lim }, 20 \%} \cdot \frac{\mathrm{SoC}}{(100 \%-20 \%)} \\
& U_{\text {cell,ch. }}=U_{\mathrm{OCV}}-i_{\text {ch. }} \frac{R_{0}}{\psi_{\text {uni, }, v}}+2 \frac{R T}{F} \ln \left(\frac{-i_{\text {lim,ch. }}}{i_{\text {ch. }}-i_{\text {lim,ch. }}}\right) \\
& U_{\text {cell,dis. }}=U_{\mathrm{OCV}}-i_{\text {dis. }} \frac{R_{0}}{\psi_{\text {uni,v }}}+2 \frac{R T}{F} \ln \left(\frac{i_{\text {lim,dis. }}-i_{\text {dis. }}}{i_{\text {lim,dis. }}}\right) \\
& U_{\text {OCV }}=U_{0}+\frac{R T}{F} \ln \left(\frac{\mathrm{SoC}}{\left(1-\mathrm{SoC}^{2}\right.}\right) \\
& p_{\text {ch. }}=U_{\text {cell,ch. }} \cdot i_{\text {ch. }}
\end{aligned}
$$

$p_{\text {dis. }}=U_{\text {cell,dis. }} \cdot i_{\text {dis. }}$

In part II, the voltage efficiency $\eta_{\mathrm{VE}}$ arises from the energy efficiency $\eta_{\mathrm{EE}}$ and coulomb efficiency $\eta_{\mathrm{CE}}$ (Eq. (33)), see Table 4. Assuming that the voltage efficiency is equal for charging and discharging, the cell voltage for discharging $U_{\text {cell,dis. }}$ is determined by Eq. (34). For the estimation of a reasonable operation, the $\mathrm{SoC}$ is again set to $50 \%$, in contrast to the $\mathrm{SoC}$ of $20 \%$ at the inlet in the CFD model.

$$
\begin{aligned}
& \eta_{\mathrm{VE}}=\frac{\eta_{\mathrm{EE}}}{\eta_{\mathrm{CE}}} \\
& U_{\text {cell,dis. }}=U_{\mathrm{OCV}} \cdot \sqrt{\eta_{\mathrm{VE}}}
\end{aligned}
$$

In part III, the calculated discharge cell voltage $U_{\text {cell,dis. }}$ of part II is used to search for a similar cell voltage $U_{\text {cell }}$ in part $I$. 
For this cell voltage $U_{\text {cell }}$, the corresponding discharge power density $p_{\text {dis. }}$ is selected out of the investigated values of part $I$. Assuming an equal discharge and charge power density, the associated cell voltage for charging is identifiable as well. The wanted nominal power density $p_{\mathrm{N}}$ results from the average value of the determined discharge power density $p_{\text {dis. }}$ and charge power density $p_{\text {ch. }}$ (Eq. (35)). The minimum limiting current density $i_{\text {lim,dis.,min }}$ and maximum limiting current density $i_{\text {lim,dis.,max }}$ arise from the nominal power density as well as the set minimum voltage $U_{\min }$ and the maximum voltage $U_{\max }$ (Eqs. (36) and (37)). The voltage limits are given in Table 4. Finally, the searched DoD is determined from the minimum and the maximum SoC after Eq. (38). Thereby, the values for the SoC are calculated after Eqs. (39) and (40).

$$
\begin{aligned}
& p_{\mathrm{N}}=\frac{p_{\text {dis. }}+p_{\text {ch. }}}{2} \\
& i_{\text {lim,dis.,min }}=\frac{p_{\mathrm{N}}}{U_{\min }} \\
& i_{\text {lim,dis.,min }}=\frac{p_{\mathrm{N}}}{U_{\text {min }}} \\
& \mathrm{DoD}=\mathrm{SoC}_{\text {max }}-\mathrm{SoC}_{\min } \\
& \mathrm{SoC}_{\min }=\frac{i_{\text {lim,dis.,min }}}{i_{\text {lim }, 20 \%}} \cdot(100 \%-20 \%) \\
& \mathrm{SoC}_{\max }=100 \%-\frac{i_{\text {lim,dis.,max }}}{i_{\text {lim }, 20 \%}} \cdot(100 \%-20 \%)
\end{aligned}
$$

\section{Component and production costs}

Coming back to the explained total costs $C_{\text {total }}$, the specific component $\operatorname{costs} c_{\text {comp }}$ are also part of Eq. (21). They include the average specific costs for the membrane $\left(300 € / \mathrm{m}^{2}\right)$, the bipolar plate $\left(100 € / \mathrm{m}^{2}\right)$ and the electrode $\left(53 € / \mathrm{m}^{2}\right)$ [34]. Since for each cell, two electrodes are needed, the specific component costs $c_{\text {comp }}$ are in total $506 € / \mathrm{m}^{2}$. Finally, the specific production costs $c_{\text {prod }}$ are taken into account in Eq. (21) to consider the financial effort, which is needed to produce the desired flow field design. The specific production $\operatorname{costs} c_{\text {prod }}$ depend strongly on the observed flow field production technique. In this context, only those production costs are taken into account, which arise from changing the plane bipolar plate surface into a surface with a flow field design. Thereby, further costs of the production such as the investment costs of the different processes are neglected. In the following, the production techniques injection moulding (IM) and end milling (EM) are investigated. In general, the beforehand observed channel volume gives a first reference on the expectable specific production costs.

For the production of the flow field design via IM, it is assumed that the variation of the input parameters does not affect the specific costs. Therefore, the specific production costs for IM $c_{\text {prod,IM }}$ amount zero. This can be explained by the fact that the flow field is directly inserted in the plate during the IM process and only minimal further processing steps are needed to complete the insertion of the flow field's structure.

In comparison, EM is a production technique, which is used for the insertion of flow field designs after the fabrication of plane plates. The expenses for machine time have to be considered by the production time $t_{\text {prod }}$, which includes again the factor 2 to consider both half cells. The chosen feed rate for EM $v_{\text {feed,EM }}$ is given in Table 4. Furthermore, a machine cost factor $c_{\mathrm{EM}}$ as well as cutter wear is taken by the cost factor $c_{\text {wear }}$ the is taken into account (Eq. (41)). As it is expected that for EM a single cutter is used, the production time for EM

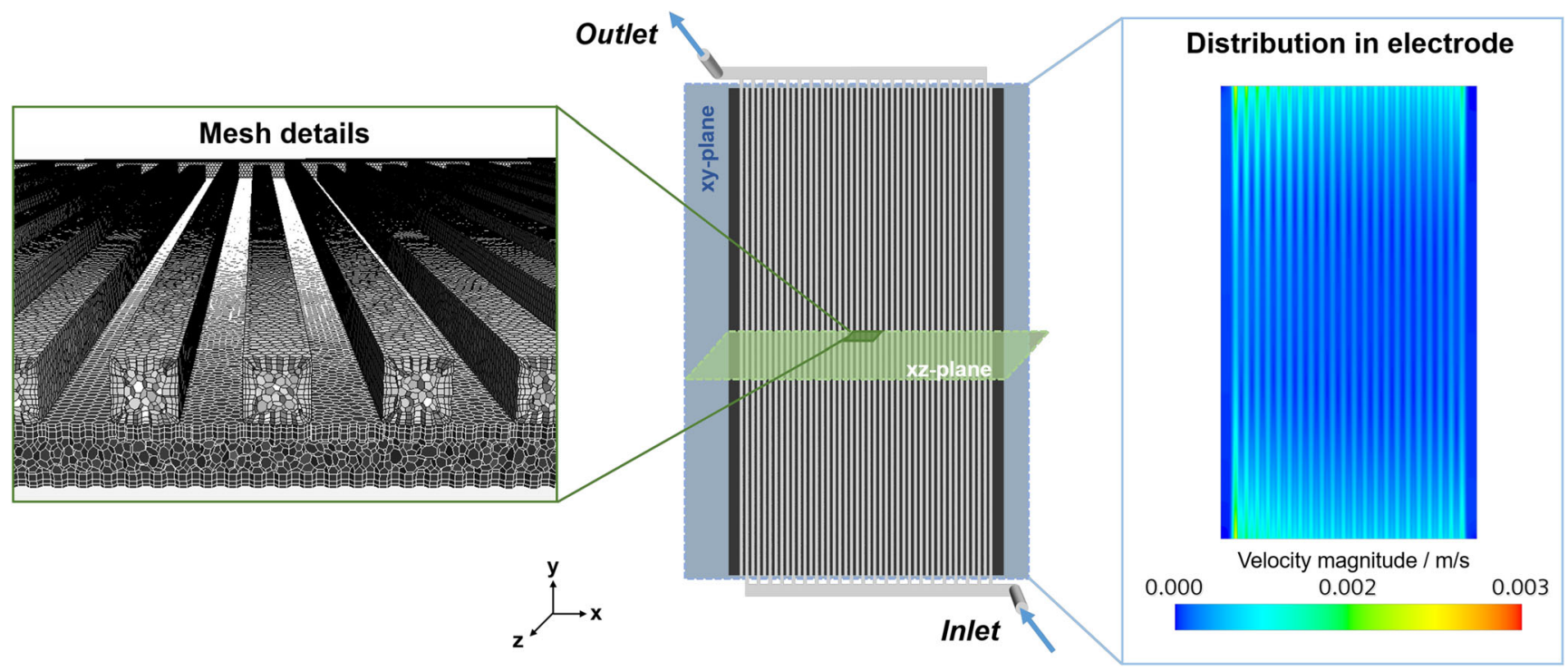

Fig. 3 Mesh details and velocity distribution for an exemplary IFF design, which was picked out of the resulting designs from the variation of the channel and land dimensions 


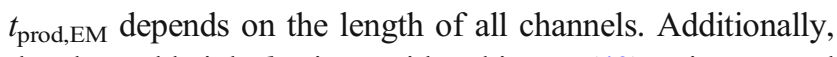
the channel height $h_{\mathrm{ch}}$ is considered in Eq. (43). It is assumed that for an acceptable production quality, the cutter has to pass more often through deep channels than through flat ones. For EM, first a step for roughing and thereafter a step of finishing is needed. Therefore, a factor of 2 is implemented in Eq. (43).

a

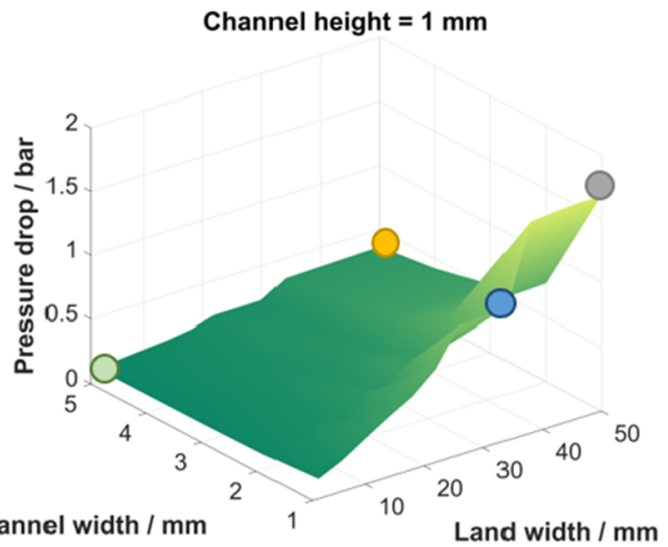

b

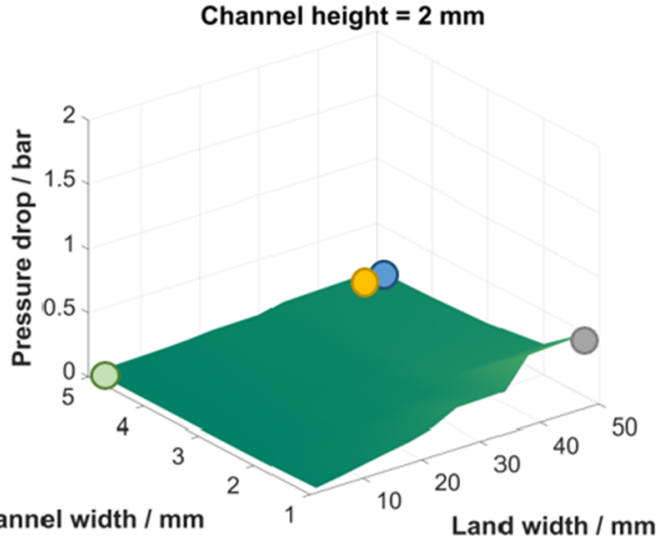

C

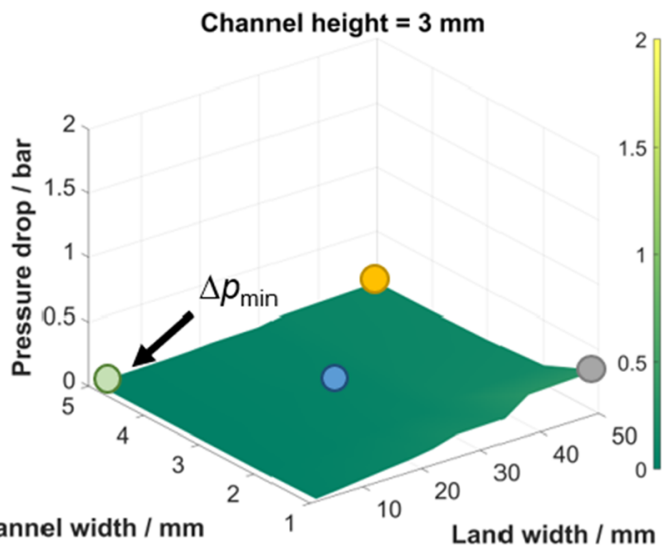

$C_{\text {prod,EM }}=c_{\mathrm{EM}} \cdot t_{\text {prod,EM }}+l_{\text {prod,EM }} \cdot c_{\text {wear,M }}$

$t_{\text {prod,EM }}=2 \cdot\left[\frac{l_{\text {prod,EM }}}{v_{\text {feed,EM }}}\right]$

$l_{\text {prod,EM }}=\frac{h_{\mathrm{ch}}}{0.0005 \mathrm{~m}} \cdot\left(2 \cdot n_{\mathrm{ch}} \cdot l_{\mathrm{ch}}\right) \cdot 2$

d

Channel height $=1 \mathrm{~mm}$

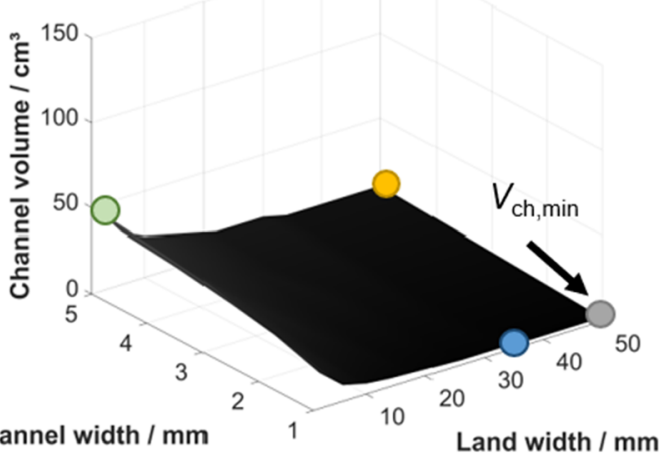

$\mathbf{e}$

Channel height $=2 \mathrm{~mm}$

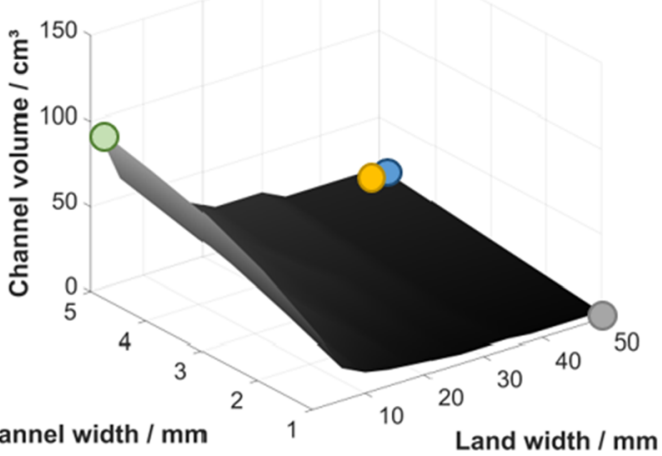

$\mathbf{f}$

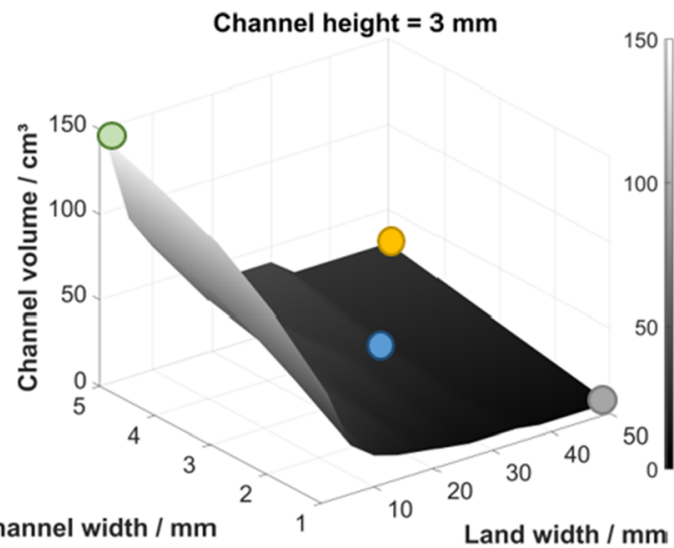

OLow pressure drop $\bigcirc$ Low channel volume $\mathrm{High}$ uniformity index $\mathrm{High}$ limiting current density $\Delta p_{\min }$ Overall lowest pressure drop

$V_{\text {ch,min }}$ Overall lowest channel volume

Fig. 4 Pressure drop (a-c) and channel volume (d-f) in dependence of the channel height and width as well as land width. Highlights are set on the specifications for the best design regarding the observed system parameter 


\section{Results and discussion}

The CFD-based results of this study are presented as follows. First, the results of an exemplary IFF design are explained. Subsequently, the simulation results for four observed system parameters, which are the pressure drop, the volume of the flow

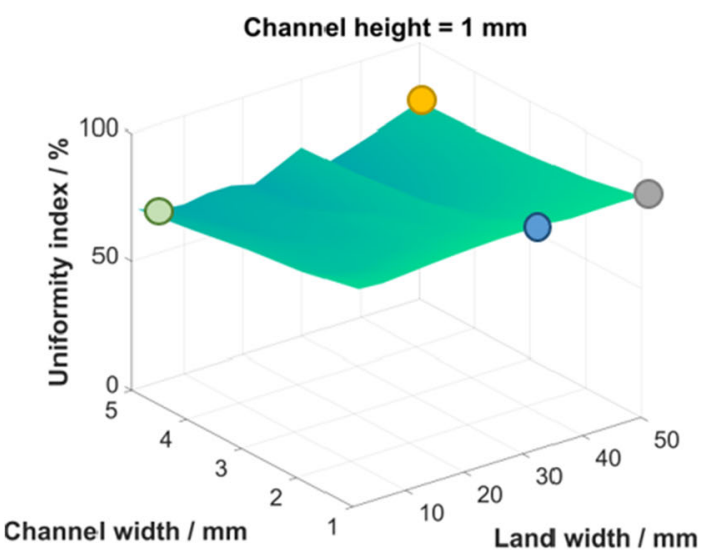

b

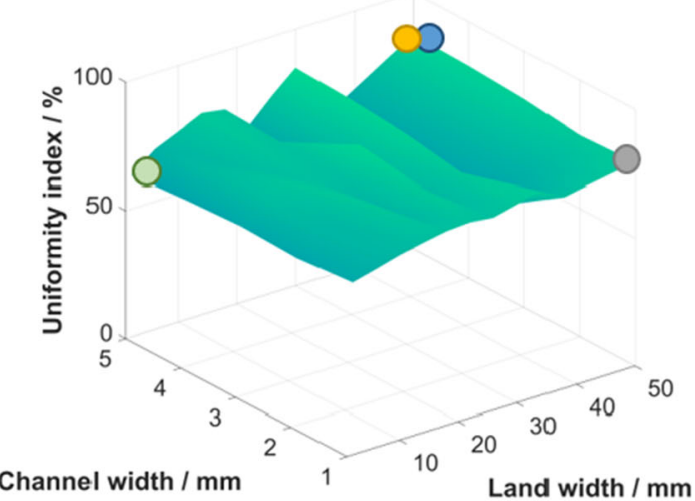

C

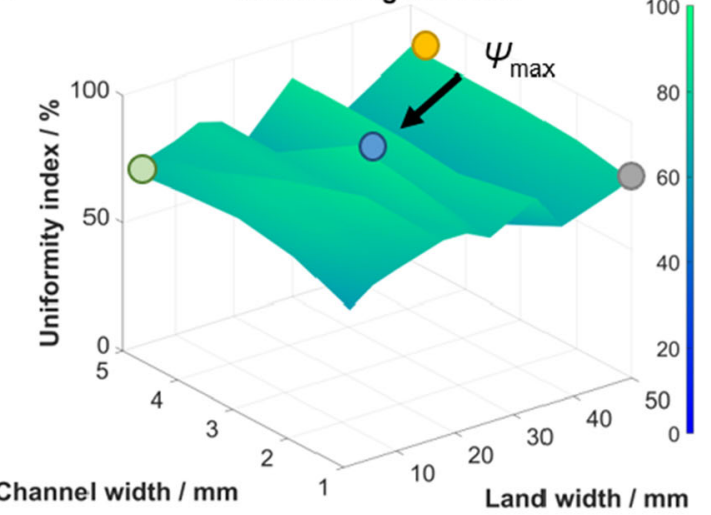

field channels, the uniformity index and the limiting current density, are illustrated for different land and channel width as well as channel height. Further, the designs, which lead to the desired value of each system parameter, are analysed in detail. Thereafter, the results of the pump and nominal power density are visualized in dependence of the channel dimensions. These
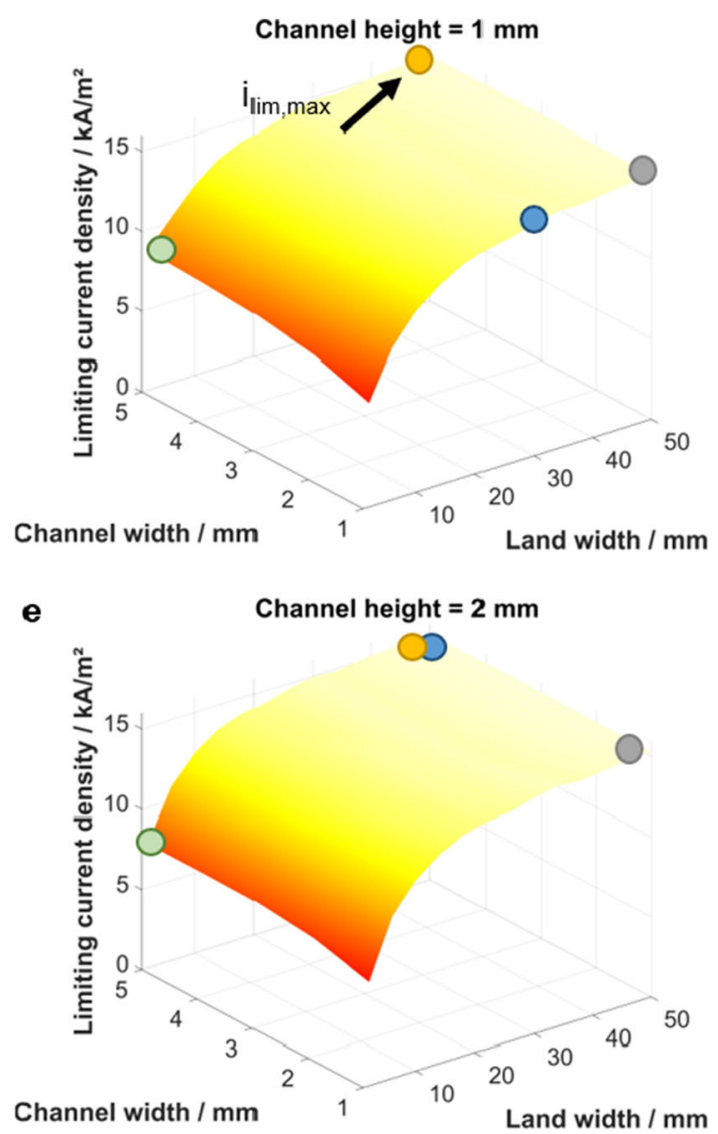

$\mathbf{f}$

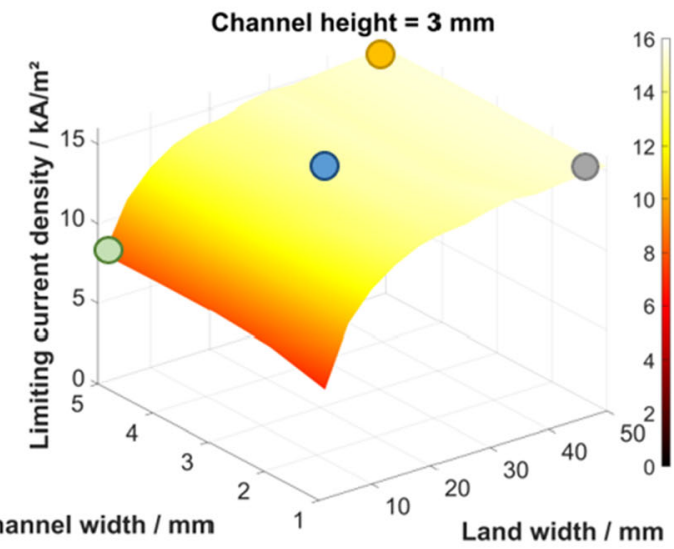

\section{OLow pressure drop $\bigcirc$ Low channel volume $\mathrm{O}$ High uniformity index $\bigcirc$ High limiting current density $\Psi_{\max }$ Overall highest uniformity index $\quad \mathrm{i}_{\text {lim,max }}$ Overall highest limiting current density}

Fig. 5 Uniformity index (a-c) and limiting current density (d-f) in dependence of the channel and land width with highlights on the specifications for the best design regarding the observed system parameter 
are included in the estimation of the electrolyte, component and total costs. The dependence of the total costs on the flow field production method as well as the channel dimensions are presented with a focus on the designs, which have the lowest total costs. Finally, the dimensions of the flow field designs, which fulfil best the beforehand observed system parameters or have the lowest total costs, are compared with each other.

\section{CFD simulation results at cell level}

The variation of the land and channel width as well as channel height of an IFF design allows to analyse the results for the whole parameter range of the observed flow field dimensions.
From this parameter range, the flow characteristics of the modelled VFB half-cell are explained on the example of the IFF design, which is depicted in Fig. 3. Its channel and land dimensions are equal $\left(w_{\mathrm{ch}}=2 \mathrm{~mm}, h_{\mathrm{ch}}=2 \mathrm{~mm}, d_{\mathrm{ch}}=2 \mathrm{~mm}\right)$ and are part of the observed parameter range, which is given in Table 2 of the methods section. For this geometry, the equations of the CFD model are solved on the shown conformal mesh, see Fig. 1. For the illustrated design, the uniformity index of the velocity magnitude in the electrode volume amounts to $65 \%$. The distribution of the velocity magnitude in the electrode depends on the distance between the channels of the flow field, which is for instance visible in a plane through the electrode centre, see Fig. 3. The shown velocity
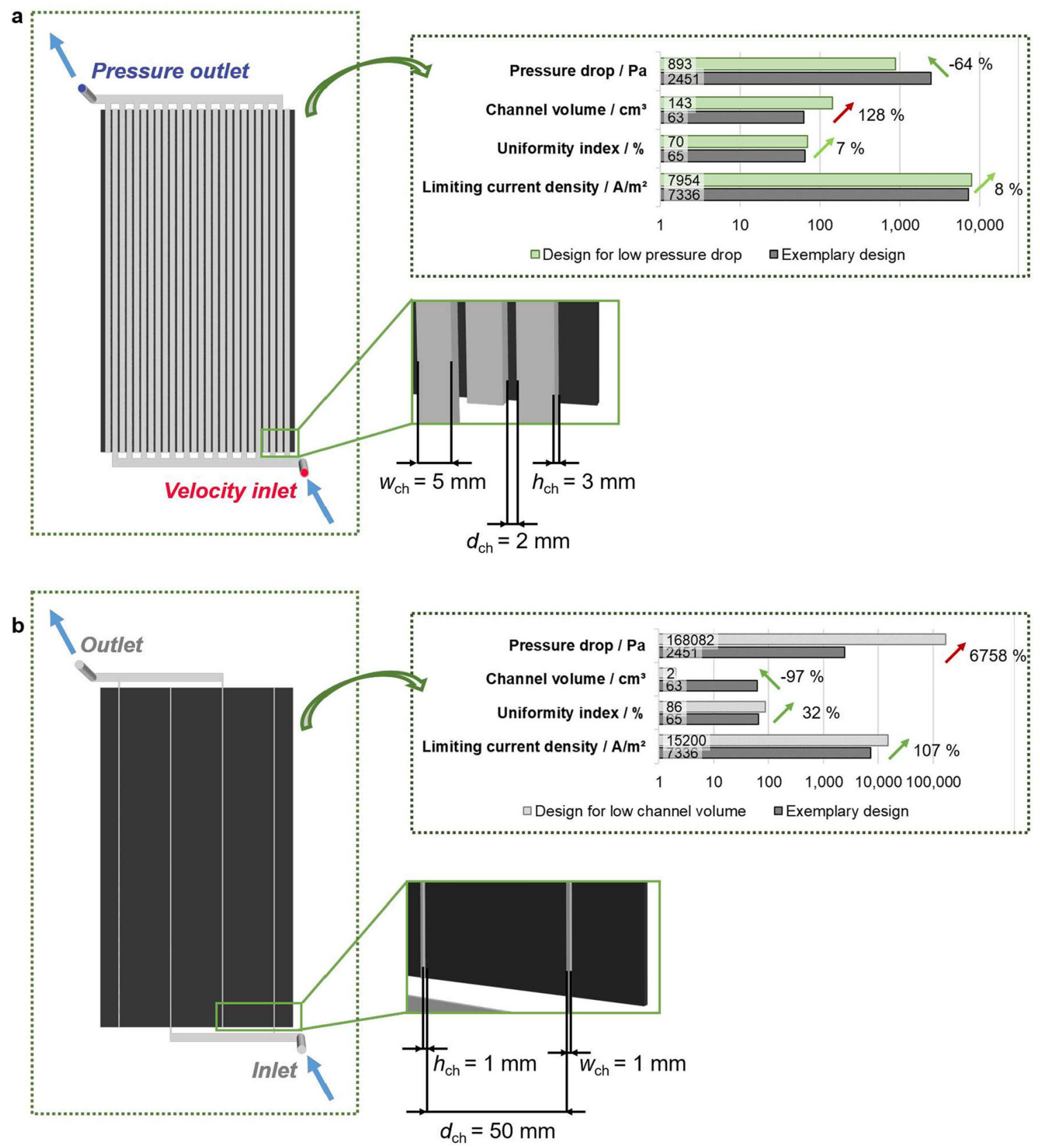

Fig. 6 IFF design with geometric dimensions and simulation results for minimum pressure drop (a) and minimum channel volume (b) 
values are quite unevenly distributed and the uniformity index is quite low. Therefore, the observation of the velocity in the plane through the electrode centre allows to draw first conclusions about the flow uniformity in the entire electrode volume. On the outer edges of the electrode, stagnation zones are noticeable, which stand out by their very low velocity magnitude's values.

For different channel and land widths in dependence of the channel height, the simulations results for the four system parameters are explained. These system parameters are, on the one hand, the pressure drop between the cell inlet and cell outlet and the volume of all flow field channels, see Fig. 4. On the other hand, the relations between the flow field dimensions and the uniformity index as well as the limiting current density are presented in Fig. 5. The channel and land dimension are varied for the values, which are given in the methods section in Table 2. The specifications, which lead to the desired value of each system parameter, are highlighted by a coloured point in Figs. 4 and 5 .

Starting with the investigation of the results towards a low pressure drop between the cell inlet and cell outlet, it is evident that the channel and land dimensions have a strong effect on the pressure drop, see Fig. 4a-c. Thereby, a large channel height and width as well as a small land width lead to a low pressure drop. The green points in the diagrams of Fig. 4 highlight those configurations, which satisfy best the demand of a low pressure drop depending on the observed channel height. An opposite behaviour can be observed for the flow field channel volume, see Fig. $4 \mathrm{~d}-\mathrm{f}$. Obviously, the channel volume gets smaller as the flow field dimensions decrease and the land width increases.
The uniformity index does not follow a general trend depending on the channel and land dimensions, see Fig. 5a-c. It mainly differs depending on the number and position of the flow field channels. The land and channel width for the highest value of the uniformity index depend on the channel height.

The behaviour of the limiting current density in dependence of the flow field dimensions is different (Fig. 5). It increases as the average velocity in the electrode rises, which enhances the mass transfer coefficient. This is the case for a growing distance between the channels, which results from an increasing land width, see Fig. 5. This is analogous for the channel width. Nevertheless, the limiting current density barely increases due to changes of large land width values. This is due to the selected boundary conditions and in particular, due to the chosen correlation equation as well as inlet $\mathrm{SoC}$, see methods section Eq. (19) and Table 3. In this case, a further increase in the land width does not lead to a significant increase of the limiting current density, as the SoC at the outlet is already very close to a value of $100 \%$. Yet, the position, where the SoC of almost $100 \%$ is reached, changes due to an increase of the land width, see later on Fig. 8. Therefore, also the visible effect in Fig. 5d-f of the channel depth on the limiting current density is comparatively low. Assuming a correlation equation, which leads to lower values of the mass transfer coefficient, clarifies that the limiting current density is the largest for a low channel height and a large land width. This design is marked in Fig. 5d.

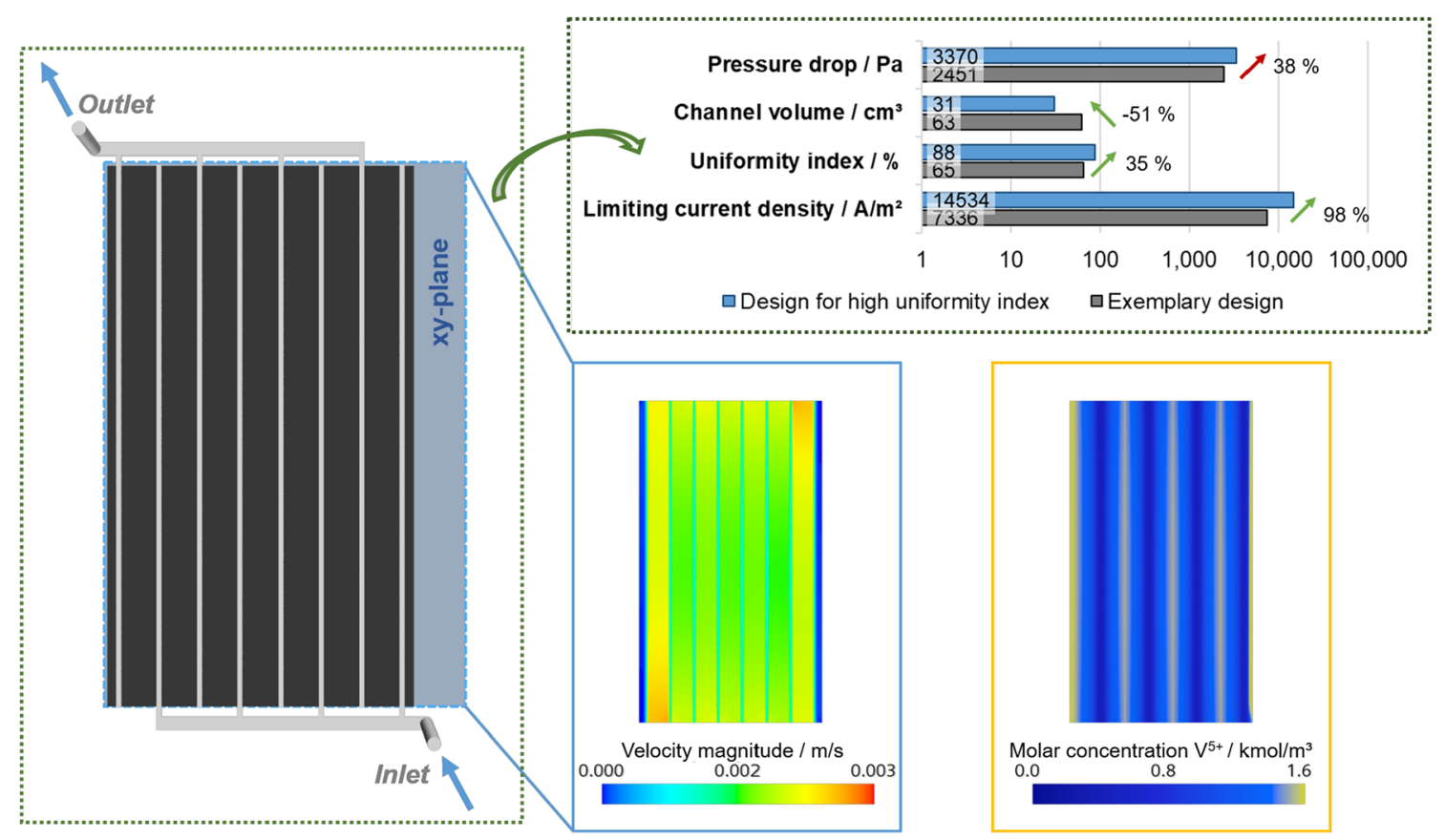

Fig. 7 Best IFF design for a very high uniformity index with its distribution of the velocity and the molar concentration in a plane through the electrode centre 
In the following, the IFF designs, which best fulfil one of the system parameters, are investigated in more detail. The IFF design, which achieves the overall lowest pressure drop, is shown in Fig. 6a. The thick, deep and narrow flow field channels are clearly visible on the geometry scene. Those lead to a decreased path length of the fluid through the porous electrode and therefore to a reduced pressure drop. However, the channel volume is drastically increased in comparison with the exemplary design, compare Fig. 3 . The best design for a low channel volume has completely opposite channel and land specifications than the one for a low pressure drop. The lowest channel volume is achieved by applying the minimum values for the channel dimensions and the maximum land width, which also leads to a high limiting current density, see Fig. 6b. The pressure drop is the highest for this design and exceeds the limit of 0.5 bar for the rule of PED by more than a factor of three.

The highest value for the uniformity index is gained in the observed parameter range for a flow field design, which has a large channel height and medium channel as well as land width $\left(w_{\mathrm{ch}}=3 \mathrm{~mm}, h_{\mathrm{ch}}=3 \mathrm{~mm}, d_{\mathrm{ch}}=22 \mathrm{~mm}\right)$, see Fig. 7. As this design cannot be identified due to an apparent trend of the uniformity index in dependence of the channel and land dimensions, it cannot be excluded that there exists another design within the observed parameter range, which might has a higher uniformity index value. A study with a smaller step size could insure the presented design to that circumstance. However, the available data basis does not give any hint that the dimensions of another design would be significantly different to the presented design. Indications of the flow uniformity within the electrode are deducible from the velocity distribution in a plane through the electrode centre, shown in Fig. 7. The values of the velocity magnitude are higher for this design and appear to be more even for these than for the exemplary design, compare Fig. 3. Furthermore, as the limiting current density of this design is already quite high, in Fig. 7 also the distribution of the molar concentration of $\mathrm{V}^{5+}$ for this plane is shown.

The maximum limiting current density is achieved by a flow field design with a low channel height and a large channel as well

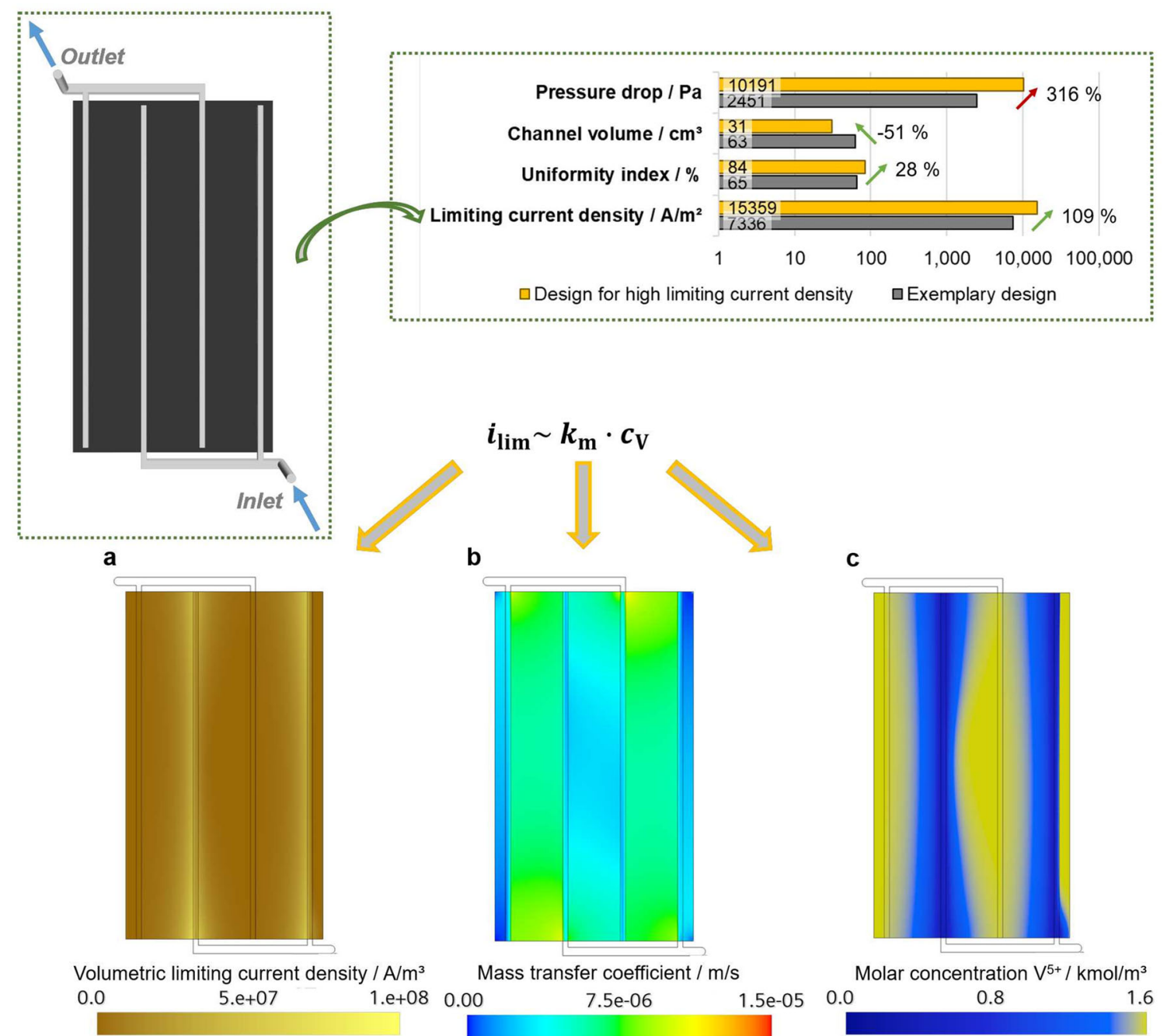

Fig. 8 Best flow field design for maximum limiting current density with the distribution in a plane through the electrode centre for volumetric limiting current density (a), mass transfer coefficient $(\mathbf{b})$ and resulting molar concentration of $\mathrm{V}^{5+}(\mathbf{c})$ 
as land width. For this design, the distribution of the limiting current density, which results from the mass transfer coefficient and the vanadium concentration, are illustrated for a plane through the electrode centre in Fig. 8. The volumetric limiting current density decreases between the channels, although the mass transfer coefficient does not strongly change, compare Figs. $8 \mathrm{a}$ and $8 \mathrm{~b}$. As explained before, the reason for this is the molar concentration of $\mathrm{V}^{5+}$, which reaches after a short distance in the electrode the maximum molar concentration and therefore a SoC of almost $100 \%$, see Fig. $8 \mathrm{c}$.

In summary, it is evident for the four analysed system parameters, that with regard to the varied input parameters, neither the

a

Channel height $=1 \mathrm{~mm}$

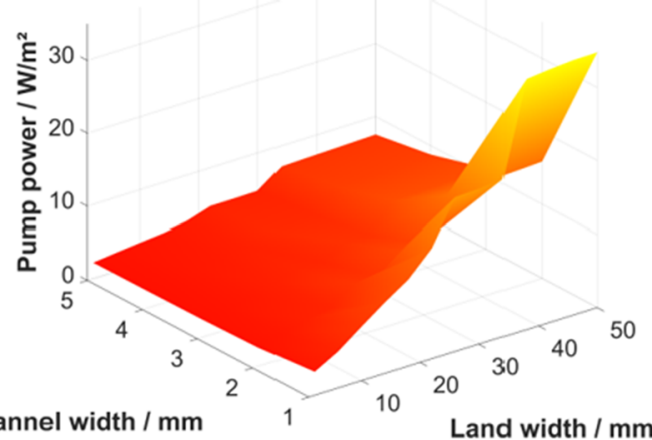

b

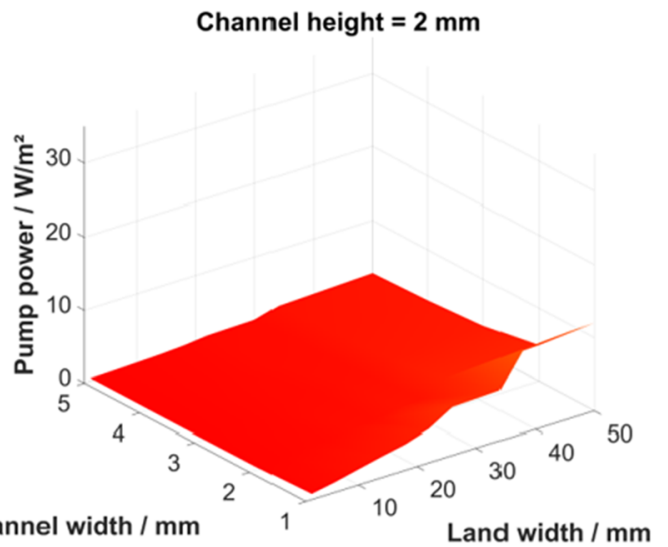

C

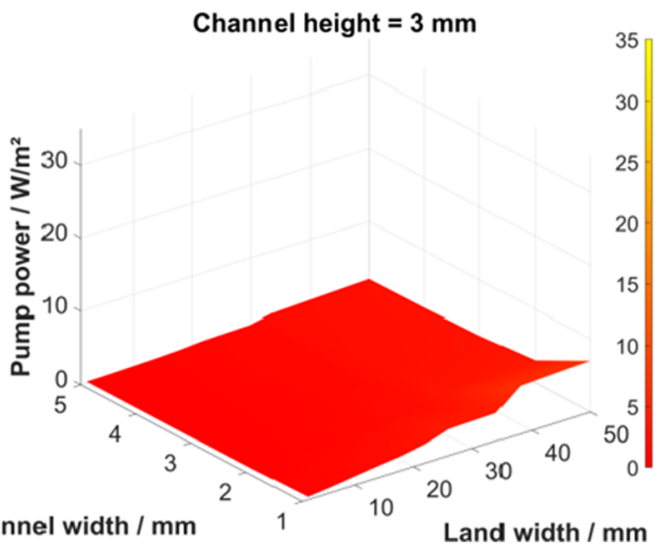

channel width or height nor the land width turn out to be similar for all presented flow field designs. Therefore, the total costs of a whole VFB system are introduced as a uniting target value. This target value allows the consideration of the four demands simultaneously, while searching for a compromise.

\section{Cost model results}

In order to be able to calculate the total costs of the VFB system, the previously considered system parameters are converted into the pump power density, the DoD and the nominal power density, see methods section.

d

Channel height $=1 \mathrm{~mm}$

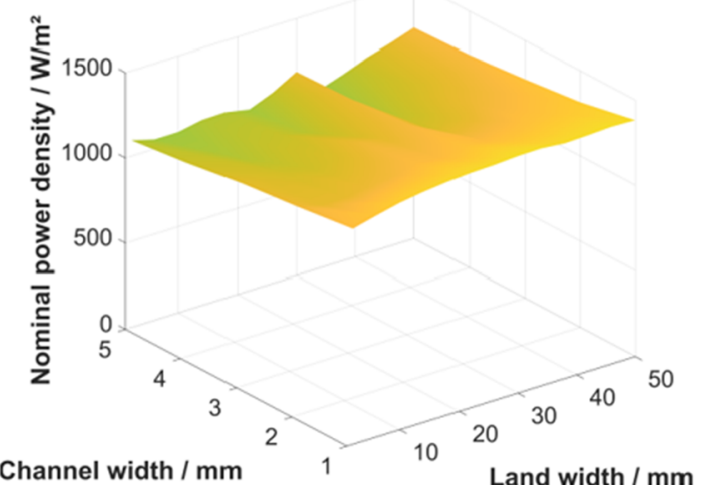

$\mathbf{e}$

Channel height $=2 \mathrm{~mm}$

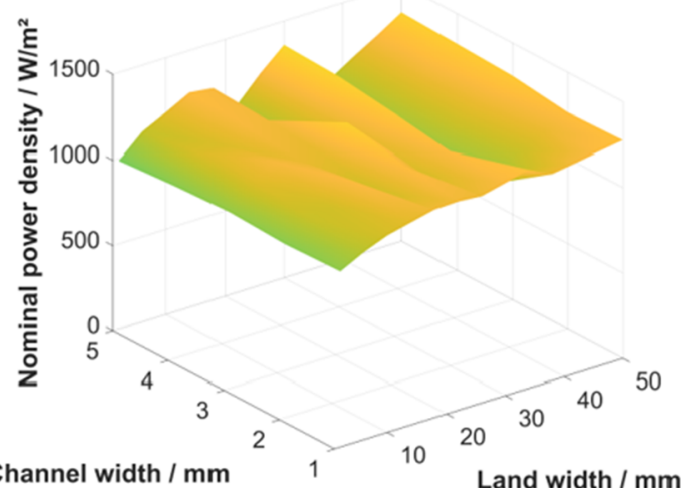

$\mathbf{f}$

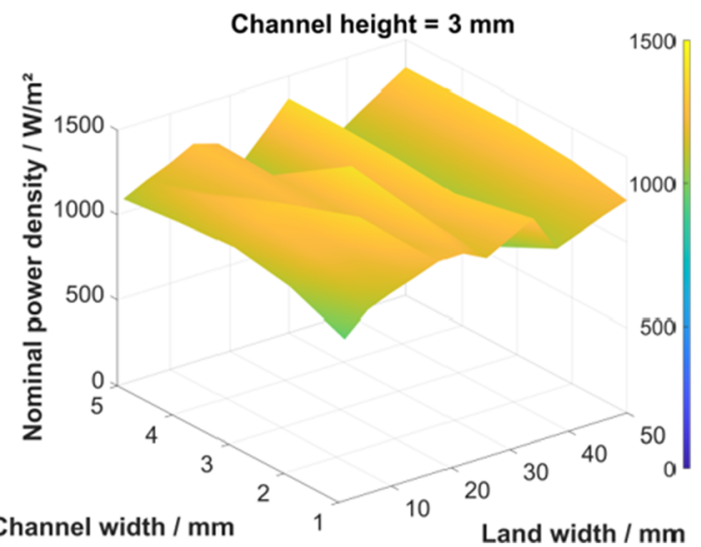

Fig. 9 Nominal power density (a-c) and pump power density (d-f) in dependence of the channel and land width 


\section{Parameters at system level}

The pump and nominal power density are shown in dependence of the channel dimensions and land width in Fig. 9. The pump power density decreases analogously to the pressure difference between cell in- and outlet with declining channel

a

Channel height $=1 \mathrm{~mm}$

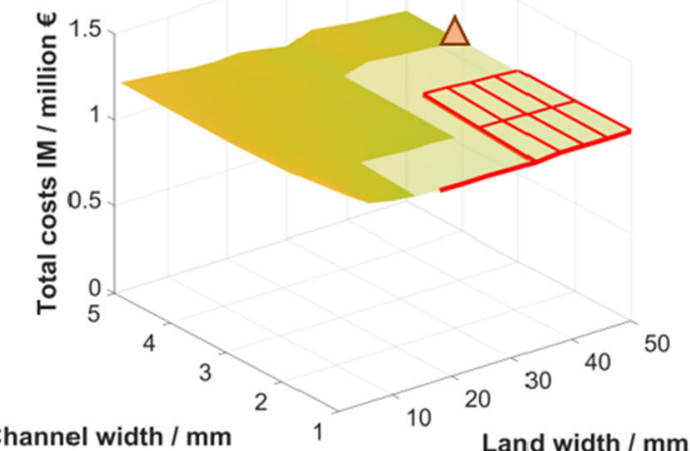

b

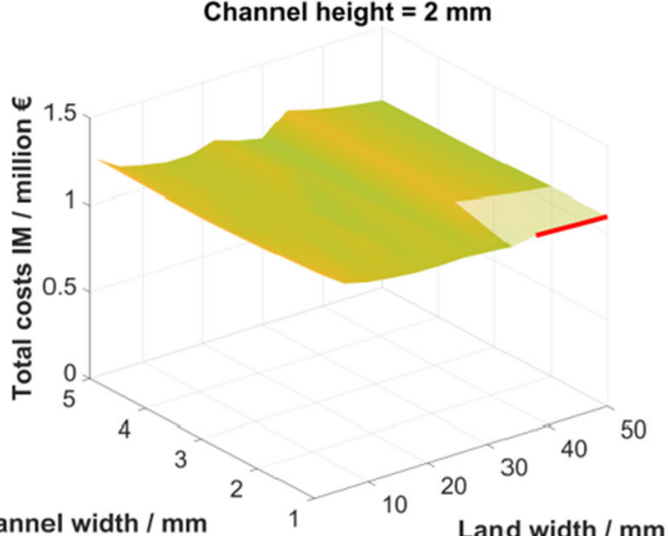

C

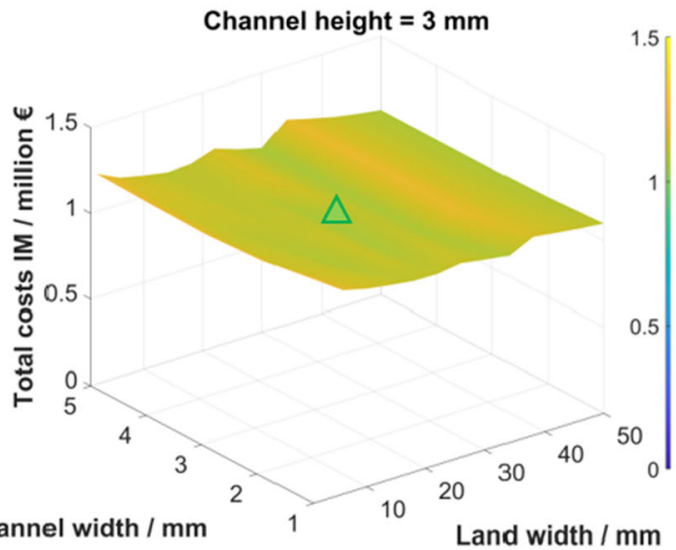

width and height and growing land width, see Fig. 9a-c and compare with the pressure difference of Fig. 4a-c. The nominal power density increases analogously to the limiting current density with growing land width. The influence of the uniformity index on the nominal power density becomes evident, as the results for the limiting current and nominal power density

d Channel height $=1 \mathrm{~mm}$

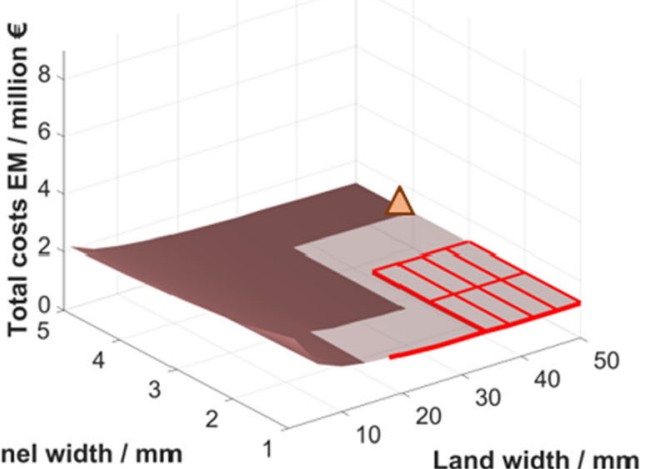

e

Channel height $=2 \mathrm{~mm}$

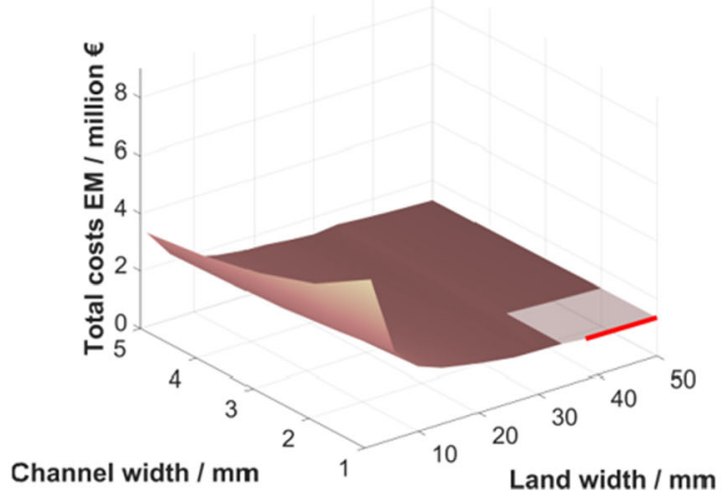

f

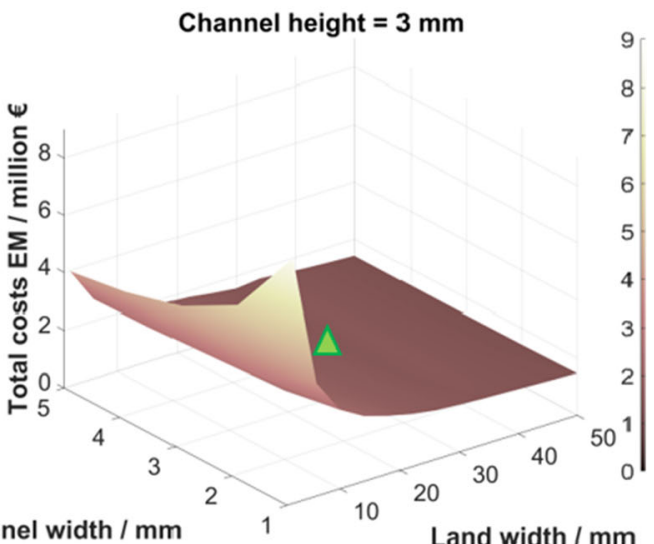

\section{$\triangle$ Lowest total costs via injection moulding $\quad \Delta$ Lowest total costs via end milling}

Fig. 10 For a production via injection moulding (a-c) and for a production via end milling (d-f), the total costs for VFB with a flow field production in dependence of the channel and land width. Red lines mark the designs, which have a pressure drop above 0.5 bar 
considerably differ, see Fig. 9d-f and compare with Fig. 5. The power demand resulting from the pump power density is significantly lower than the nominal power density.

\section{Total costs of VFB system}

The total system costs of the VFB system consist of the electrolyte, component and production costs. For the electrolyte costs, the additional capacity, which is needed to raise the pump power, is obtained by the quotient of the pump power to the nominal power, see methods section Eq. (23). The additional capacity is very low under the selected boundary conditions, due to the comparatively low pump power. Therefore, the electrolyte costs result primarily from the set nominal capacity, which is independent from the channel dimensions of the IFF design. Moreover, the costs of the electrolyte depend on the DoD, which varies between $73 \%$ and $91 \%$. The DoD has comparatively lower values for a small land width, which in return leads to increased electrolyte costs for these dimensions. In total, the geometric dimensions of the IFF design only affect the electrolyte costs to a minor extent.

The component costs directly depend on the total area of all cells of the system. These result from the ratio of the given nominal power and the needed pump power to the nominal power density. Starting from the constant nominal power, a small nominal power density leads to a large total area and vice versa, as the effect of the low pump power on the total area is rather small. Accordingly, small component costs result from a large nominal power density and the other way round, whereby the component costs are particularly large for small land width.

The total costs of the VFB, which are shown in Fig. 10a-c, are the sum of the electrolyte and component costs. This is due to the fact that it is assumed that no further flow field dependent production costs arise for the production via IM. As already outlined, the component costs and consequently the total costs depend on the total area of all cells. Therefore, for a low land width, the total costs are the largest. Moreover, for a high nominal power density, the total costs are low and vice versa, compare Figs. 10a-c and 9d-f.

For a flow field production by EM, the production costs are included in the total costs as well, see Fig. 10d-f. The specific production costs for EM are high for IFF designs with many deep channels. The lowest total costs arise for the IFF design with a small channel width and height as well as a quite large land width ( $\left.w_{\mathrm{ch}}=1 \mathrm{~mm}, h_{\mathrm{ch}}=1 \mathrm{~mm}, d_{\mathrm{ch}}=46 \mathrm{~mm}\right)$. This design is very similar to the one for the lowest channel volume, although the land width is a little bit lower. This is due to the fact, that for the small channel dimensions, the nominal power density is slightly lower for the maximum land width. This leads to some extent to higher component costs and

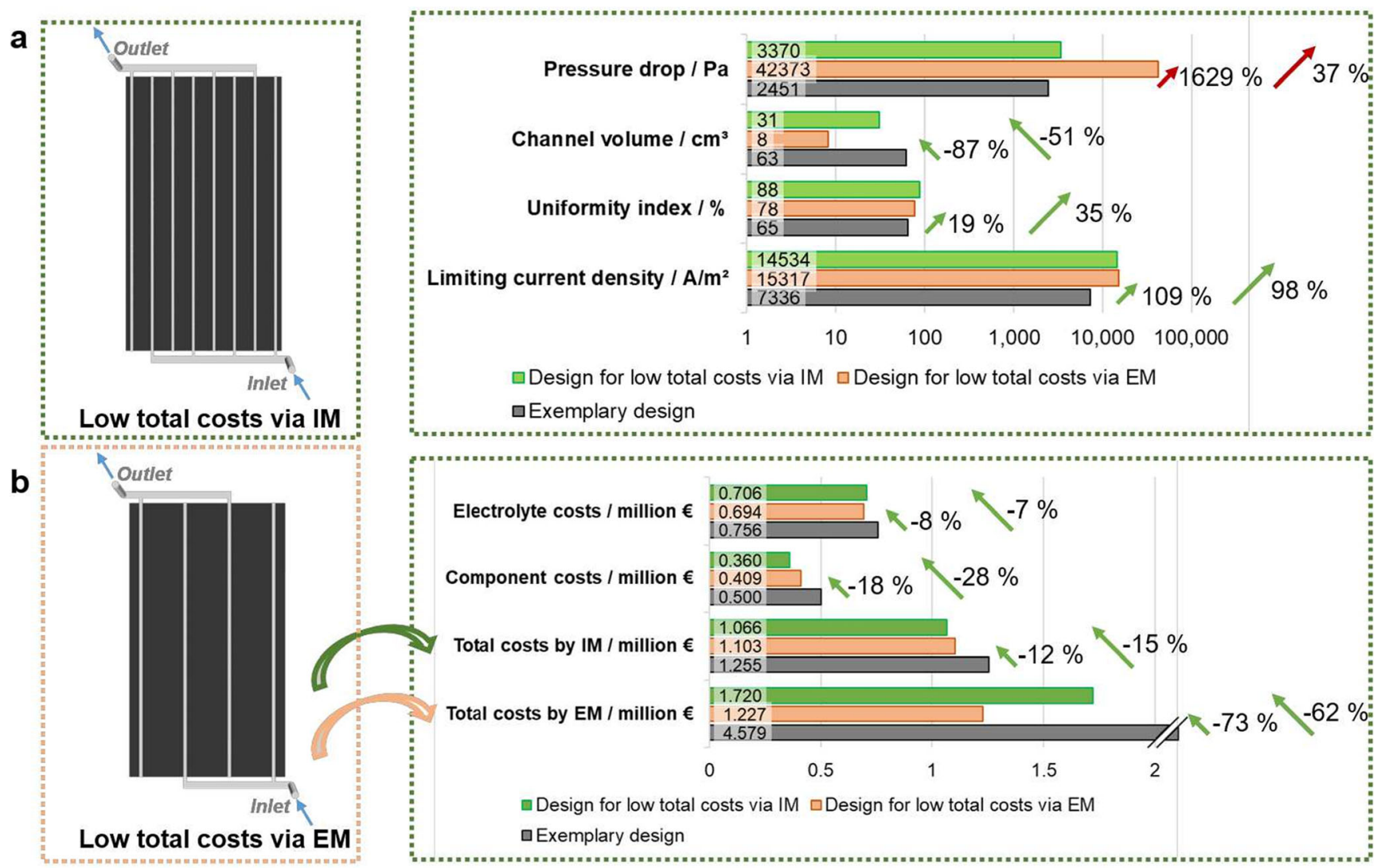

Fig. 11 Comparison of best flow field designs for minimum total costs by the flow field production via injection moulding (a) and via end milling (b) 

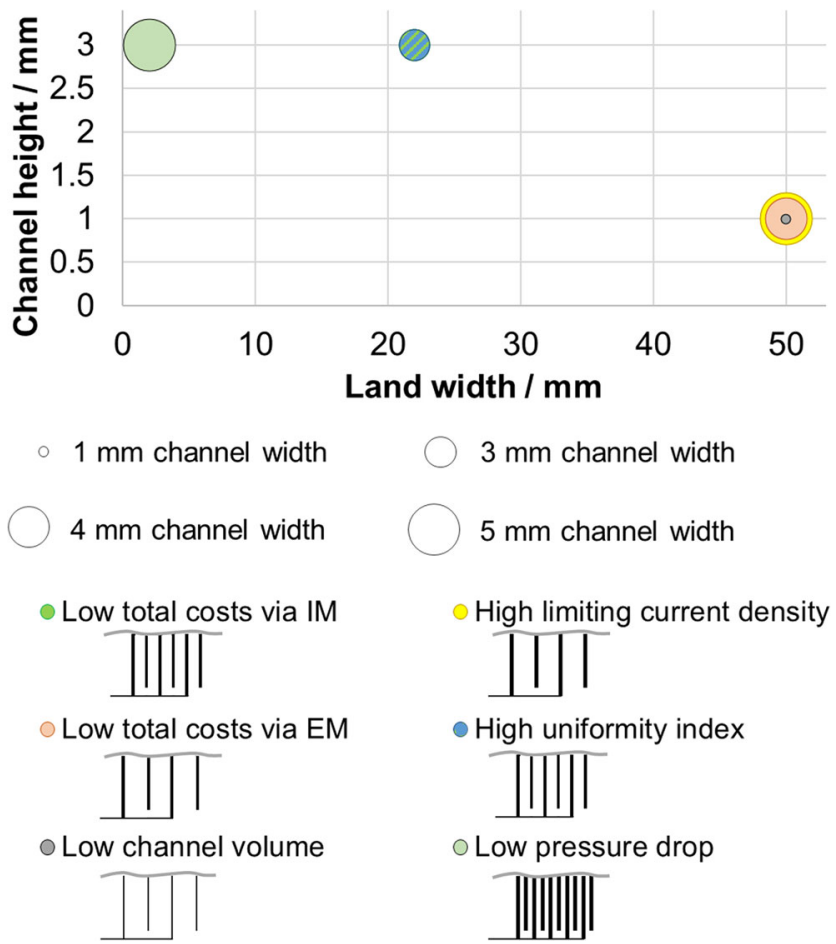

Fig. 12 Channel and land width as well as channel height for all designs reaching best each system parameters or minimum total costs with a rough geometry sketch of the flow field for each design

accordingly higher total costs. Yet, for this design, the pressure drop is larger than 0.5 bar and thereby exceeds the upper limit of the allowed pressure by PED restrictions. Excluding all designs with a pressure drop above 0.5 bar leads within the observed parameter range to a design, which has a large land and medium channel width and a low channel height ( $w_{\mathrm{ch}}=$ $4 \mathrm{~mm}, h_{\mathrm{ch}}=1 \mathrm{~mm}, d_{\mathrm{ch}}=50 \mathrm{~mm}$ ), see Fig. $11 \mathrm{~b}$. Consequently, the selection of the flow field design with the minimum total costs for a production by EM strongly depends on the upper limit of the allowed pressure drop. Therefore, for instance changing the permeability of the electrode or even the electrode material or the volume flow rate might result in a different best design.
In Fig. 10 all designs are marked by a red line, which have a pressure difference between cell in- and outlet above 0.5 bar. Furthermore, such areas are marked by a transparent colour, which represent the transition zones between those designs having a pressure drop above or bellow 0.5 bar.

The design, which achieves the minimum total costs for the production via IM, has a large channel width and height as well as a medium land width ( $w_{\mathrm{ch}}=3 \mathrm{~mm}, h_{\mathrm{ch}}=3 \mathrm{~mm}, d_{\mathrm{ch}}=22 \mathrm{~mm}$ ). The geometry of this design is shown in Fig. 11a. It leads to a lower pressure drop and higher uniformity index in comparison to the flow field design with the lowest production costs via EM.

There are just minor differences in the electrolyte and component costs for the two designs with the minimal total costs. The electrolyte costs are slightly larger for the IFF design by $\mathrm{IM}$, as its achievable DoD is smaller. Yet, due to its higher nominal power density, its component costs are lower than those of the design by EM. Yet, for both designs the electrolyte and component costs are lower than these of the exemplary design of Fig. 3, as this design has a lower nominal power density and a lower DoD. Assuming that the two designs with the minimal total costs are manufactured by IM leads to quite similar costs. As expected, the total costs are lower for the design, which has the lowest total costs via IM. For the production method EM, the production costs have an impact on the total costs. The costs for the flow field design, which is best for IM, are higher for the production technique EM than the costs are for the design with the minimal total costs by EM. Although, the total costs are significantly larger for the exemplary design, which is mainly due to its high number of flow field channels.

It was shown, that the best IFF design strongly depends on the observed goal parameter. The precise choice of dimensions for the IFF design allows to reduce the costs of a VFB system. In comparison with the exemplary design, minor saving opportunities of less than $10 \%$ result for the electrolyte costs and medium saving opportunities with less than $30 \%$ for the component costs, see Fig. 11. Large saving of more than $60 \%$ are achievable for the total costs concerning the production technique EM.
Table 5 Mesh data and simulation results of the exemplary flow field design for the medium and fine mesh

\begin{tabular}{llll}
\hline Parameter & Name & Value & Unit \\
\hline$N_{\text {fine }}$ & Cell number for fine mesh & $21,968,680$ & - \\
$N_{\text {middle }}$ & Cell number for middle mesh & $10,389,090$ & - \\
$p_{\text {fine }}$ & Pressure drop for fine mesh & 2490.71 & $\mathrm{~Pa}$ \\
$p_{\text {middle }}$ & Pressure drop for middle mesh & 2446.29 & $\mathrm{~Pa}$ \\
$\psi_{\text {fine }}$ & Volume uniformity for fine mesh & 65.144 & $\%$ \\
$\psi_{\text {middle }}$ & Volume uniformity for middle mesh & 65.188 & $\%$ \\
$i L_{\text {fine }}$ & Limiting current density for fine mesh & 7321.736 & $\mathrm{~A} / \mathrm{m}^{2}$ \\
$i L_{\text {middle }}$ & Limiting current density for middle mesh & 7329.194 & $\mathrm{~A} / \mathrm{m}^{2}$ \\
\hline
\end{tabular}


Table 6 Extrapolated values for the mesh evaluation of the exemplary flow field design

\begin{tabular}{llll}
\hline Parameter & Name & Value & Unit \\
\hline$p_{\infty}$ & Pressure drop for zero mesh size & 2530.56 & $\mathrm{~Pa}$ \\
$\psi_{\infty}$ & Volume uniformity for zero mesh size & 65.105 & $\%$ \\
$i L_{\infty}$ & Limiting current density for zero mesh size & 7315.045 & $\mathrm{~A} / \mathrm{m}^{2}$ \\
$\mathrm{ERE}_{p}$ & Extrapolated relative error for pressure drop & 3.4 & $\%$ \\
$\mathrm{ERE}_{\psi}$ & Extrapolated relative error for uniformity index & 0.1 & $\%$ \\
$\mathrm{ERE}_{i L}$ & Extrapolated relative error for limiting current density & 0.2 & $\%$ \\
\hline
\end{tabular}

\section{Result combination}

The channel width and height as well as land width for the observed best designs are summarized in Fig. 12 . Additionally, a sketch of each design is shown in the figure's legend to further illustrate their dimensions. The channel and land dimensions can be contrary depending on the aspired goal parameter, which is the case for instance for a low pressure drop and a low channel volume. For the design of the lowest total costs by the production via EM, the flow field dimensions are very similar to those of the minimum channel volume. Yet, this design is not applicable due to the PED restrictions. Therefore, a larger channel and land width has to be applied. This design has quite similar dimensions to the one of the highest limiting current density. For the total costs by the production via IM the resulting IFF turns out to have channel and land dimensions, which are equal to those of the design with the highest uniformity index. Its dimensions are in the middle of the beforehand four observed system parameters. In dependence of the boundary conditions, the definition of the total costs allows to find a compromise for the different requests.

\section{Conclusion}

For a large number of different flow field channel and land dimensions, the four system parameters, pressure drop, volume of the flow field channels, uniformity index of the velocity and limiting current density, were systematically evaluated. Based on the CFD model of an exemplary IFF, the designs which allow to achieve the desired value of each of the system parameters were presented. As no single flow field design was optimal for all system parameters, the total costs of the VFB system in dependence of the flow field characteristics were introduced. Their definition allows the identification of a superior flow field design for the VFB, which takes the different system parameters simultaneously into account. For this evaluation of the entire VFB system, also the pump and nominal power density as well as the DoD in dependence of the flow field's channel and land dimensions were considered. They were used to estimate the costs for the electrolyte, the flow field production and the component, which together give the total costs of the VFB system. Finally, flow field designs were achieved, which cause less than half of the total costs for a production by EM in comparison to an initial exemplary design. Accordingly, the identified flow field designs lead to desired low total costs of a VFB system.

In this study, it was shown that many relations exist between the flow field dimensions, the boundary conditions, the system parameters and the VFB costs. Thereby, the analysis of the uniformity index might be enhanced in the future, as it strongly influences the resulting nominal power density. In prospective studies, the described approach can be applied for other cell sizes as well as for further flow field geometries and designs. Moreover, this method is applicable for other electrode materials and types of RFB.

\section{Appendix}

The ERE is calculated in dependence of the field variable $\delta$ by Eqs. (44), Eq. (45) and Eq. (46), which are taken from [24] for the mesh evaluation of particle packings. The fine mesh has a base size of $0.5 \mathrm{~mm}$.

$\delta_{\infty}=\delta_{\text {fine }}+\frac{\delta_{\text {fine }}-\delta_{\text {middle }}}{r_{\mathrm{g}}^{2}-1}$

$r_{\mathrm{g}}=\sqrt{\frac{N_{\text {fine }}}{N_{\text {middle }}}}$

$\mathrm{ERE}=\left|\frac{\delta_{\infty}-\delta_{\text {middle }}}{\delta_{\infty}}\right|$

The values of the observed pressure drop, velocity uniformity and limiting current density for a fine and a medium size mesh with the number of mesh cells $\mathrm{N}$ are listed in Table 5. It is noticeable, that the values of Table 6 for the exemplary flow field design differ to a slight extend in comparison with the values for this design given in the Results and Discussion section. This is due small deviations in the starting conditions of the simulations, which result from the requirements of the 
parameter study. The calculated results are presented in Table 6.

Acknowledgments Part of this study was carried out within the project "Extrusionsplatte" (03ET6050D), for which financial support by the Federal Ministry of Economic Affairs and Energy (BMWi) is gratefully acknowledged.

Authors'contributions Not applicable.

Availability of data and material Not applicable.

Code availability Not applicable.

\section{Symbols used}

\begin{tabular}{|c|c|c|}
\hline Symbols & Unit & Meaning \\
\hline$a$ & $\mathrm{~m}^{-1}$ & Specific surface area \\
\hline$c$ & $\mathrm{~mol} \mathrm{~m}^{-3}$ & Molar concentration \\
\hline$c$ & $€ \mathrm{~m}^{-2}$ & Specific costs \\
\hline C & $€$ & Costs \\
\hline$d$ & $\mathrm{~m}$ & Diameter \\
\hline$d_{\mathrm{ch}}$ & $\mathrm{m}$ & Land width \\
\hline$D$ & $\mathrm{~m}^{2} \mathrm{~s}^{-1}$ & Diffusion coefficient \\
\hline DoD & - & Depth of discharge \\
\hline$F$ & $\mathrm{C} \mathrm{mol}^{-1}$ & Faraday’s constant \\
\hline$h_{\mathrm{ch}}$ & $\mathrm{m}$ & Channel height \\
\hline$i$ & $\mathrm{~A} \mathrm{~m}^{-2}$ & Current density \\
\hline$i_{\mathrm{vol}}$ & $\mathrm{A} \mathrm{m}^{-3}$ & Volumetric current density \\
\hline K & $\mathrm{m}^{2}$ & Electrode permeability \\
\hline$k_{\mathrm{m}}$ & $\mathrm{m} \mathrm{s}^{-1}$ & Mass transfer coefficient \\
\hline$l$ & $\mathrm{~m}$ & Length \\
\hline$\eta$ & - & Efficiency \\
\hline$n$ & - & Number \\
\hline$p$ & $\mathrm{~Pa}$ & Pressure \\
\hline$P$ & $\mathrm{~W}$ & Power \\
\hline $\mathbf{P}_{\mathrm{i}}$ & $\mathrm{kg} \mathrm{m}^{-4}$ & Inertial resistance tensor \\
\hline $\mathbf{P}_{\mathrm{v}}$ & $\mathrm{kg} \mathrm{m}^{-3} \mathrm{~s}^{-1}$ & Viscous resistance tensor \\
\hline$Q$ & Ws & Capacity \\
\hline$R$ & $\mathrm{~J} \mathrm{~K}^{-1} \mathrm{~mol}^{-1}$ & Universal gas constant \\
\hline$R_{0}$ & $\Omega \mathrm{cm}^{2}$ & Specific cell resistance \\
\hline$R e$ & - & Reynolds number \\
\hline$S$ & $\mathrm{~mol} \mathrm{~m}^{-3} \mathrm{~s}^{-1}$ & Source term \\
\hline$S c$ & - & Schmidt number \\
\hline$S h$ & - & Sherwood number \\
\hline $\mathrm{SoC}$ & - & State of charge \\
\hline$t$ & $\mathrm{~s}$ & Time \\
\hline$T$ & $\mathrm{~K}$ & Temperature \\
\hline $\mathbf{T}$ & $\mathrm{kg} \mathrm{m}^{-1} \mathrm{~s}^{-2}$ & Stress tensor \\
\hline$U$ & V & Voltage \\
\hline$v$ & $\mathrm{~m} \mathrm{~s}^{-1}$ & Velocity \\
\hline$V$ & $\mathrm{~m}^{3}$ & Volume \\
\hline$w_{\mathrm{ch}}$ & $\mathrm{m}$ & Channel width \\
\hline
\end{tabular}

$\mathrm{kg} \mathrm{mol}{ }^{-1}$

$W_{i}$

$Y_{i}$

$\mathrm{z}$

Greek symbols

$\beta_{\mathrm{F}}$

$\delta$

$\varepsilon$

$\mu$

$\rho$

$\rho$

$\sigma_{\mathrm{t}}$

$\tau$

$\psi$

Sub- and Superscripts

0

c

$\mathrm{c}$

CE

ch

ch.

comp

dis.

EE

EM

f

F

fine

IM

i

iL

in

$\lim$

$\mathrm{m}$

$\max$

middle

$\min$

mix

$\mathrm{N}$

OCV

$\mathrm{p}$

PE

prod

$\mathrm{s}$

$\mathrm{t}$

uni

$\mathrm{v}$

$v$

$\mathrm{V}$

VE

V4+

V4+

wear

$Y_{i}$

$\psi$
Molecular weight of species i

Mass fraction of species $i$

Electron stoichiometry

Forchheimer constant

Field variable

Porosity

Dynamic viscosity

Density

Turbulent Schmidt number

Tortuosity

Uniformity index

Initial

Compressed

Cell

Coulombic efficiency

Channel

Charge

Component

Discharge

Energy efficiency

End milling

Fibre

Forchheimer

Fine mesh

Injection moulding

Inertial

Limiting current density

Inlet

Limiting

Mass

Maximum

Middle mesh

Minimum

Mixture

Nominal

Open circuit voltage

Pressure drop

Positive electrolyte

Production

Superficial

Turbulent

Uniformity

Viscous

Velocity

Vanadium

Voltage efficiency

Vanadium 4+

Cutter wear

For mass fraction of species $i$

Uniformity index 


\begin{tabular}{lll}
$\infty$ & - & Zero mesh size \\
Abbreviations & & \\
CFD & - & Computational fluid dynamics \\
DoD & - & Depth of discharge \\
EM & - & End milling \\
ERE & & Extrapolated relative error \\
IFF & - & Interdigitated flow field \\
IM & - & Injection moulding \\
PE & - & Positive electrolyte \\
PED & - & Pressure equipment directive \\
SoC & - & State of charge \\
VFB & - & Vanadium redox-flow batteries \\
\hline
\end{tabular}

Funding Open Access funding enabled and organized by Projekt DEAL. Funding was provided by the Federal Ministry of Economic Affairs and Energy (BMWi).

\section{Declarations}

Conflict of interest The authors have no relevant conflicts of interest to declare.

Open Access This article is licensed under a Creative Commons Attribution 4.0 International License, which permits use, sharing, adaptation, distribution and reproduction in any medium or format, as long as you give appropriate credit to the original author(s) and the source, provide a link to the Creative Commons licence, and indicate if changes were made. The images or other third party material in this article are included in the article's Creative Commons licence, unless indicated otherwise in a credit line to the material. If material is not included in the article's Creative Commons licence and your intended use is not permitted by statutory regulation or exceeds the permitted use, you will need to obtain permission directly from the copyright holder. To view a copy of this licence, visit http://creativecommons.org/licenses/by/4.0/.

\section{References}

1. Sánchez-Díez E, Ventosa E, Guarnieri M et al (2021) Redox flow batteries: status and perspective towards sustainable stationary energy storage. J Power Sources 481:228804. https://doi.org/10.1016/ j.jpowsour.2020.228804

2. Soloveichik GL (2015) Flow batteries: current status and trends. Chem Rev 115:11533-11558. https://doi.org/10.1021/cr500720t

3. Cunha Á, Martins J, Rodrigues N et al (2015) Vanadium redox flow batteries: a technology review. Int J Energy Res 39:889-918. https://doi.org/10.1002/er.3260

4. Arenas LF, Ponce de León C, Walsh FC (2019) Redox flow batteries for energy storage: their promise, achievements and challenges. Curr Opin Electrochem 16:117-126. https://doi.org/10.1016/j. coelec.2019.05.007

5. Sun J, Zheng M, Yang Z et al (2019) Flow field design pathways from lab-scale toward large-scale flow batteries. Energy 173:637646. https://doi.org/10.1016/j.energy.2019.02.107

6. Arenas LF, Ponce de León C, Walsh FC (2017) Engineering aspects of the design, construction and performance of modular redox flow batteries for energy storage. J Energy Storage 11:119-153. https://doi.org/10.1016/j.est.2017.02.007
7. Ke X, Prahl JM, Alexander JID et al (2018) Rechargeable redox flow batteries: flow fields, stacks and design considerations. Chem Soc Rev 47:8721-8743. https://doi.org/10.1039/C8CS00072G

8. Zhang BW, Lei Y, Bai BF et al (2019) A two-dimensional model for the design of flow fields in vanadium redox flow batteries. Int $\mathrm{J}$ Heat Mass Transf 135:460-469. https://doi.org/10.1016/j. ijheatmasstransfer.2019.02.008

9. Gerhardt MR, Wong AA, Aziz MJ (2018) The effect of Interdigitated Channel and land dimensions on flow cell performance. J Electrochem Soc 165:A2625-A2643. https://doi.org/10. $1149 / 2.0471811$ jes

10. Zeng Y, Li F, Lu F et al (2019) A hierarchical interdigitated flow field design for scale-up of high-performance redox flow batteries. Appl Energy 238:435-441. https://doi.org/10.1016/j.apenergy.2019.01.107

11. Akuzum B, Alparslan YC, Robinson NC et al (2019) Obstructed flow field designs for improved performance in vanadium redox flow batteries. J Appl Electrochem 49:551-561. https://doi.org/10. 1007/s10800-019-01306-1

12. Houser J, Clement J, Pezeshki A et al (2016) Influence of architecture and material properties on vanadium redox flow battery performance. J Power Sources 302:369-377. https://doi.org/10.1016/j. jpowsour.2015.09.095

13. Chen C-H, Yaji K, Yamasaki S et al (2019) Computational design of flow fields for vanadium redox flow batteries via topology optimization. J Energy Storage 26:100990. https://doi.org/10.1016/j.est.2019.100990

14. Yoon SJ, Kim S, Kim DK (2019) Optimization of local porosity in the electrode as an advanced channel for all-vanadium redox flow battery. Energy 172:26-35. https://doi.org/10.1016/j.energy.2019.01.101

15. Forner-Cuenca A, Brushett FR (2019) Engineering porous electrodes for next-generation redox flow batteries: recent progress and opportunities. Curr Opin Electrochem 18:113-122. https:// doi.org/10.1016/j.coelec.2019.11.002

16. Chen W, Kang J (2020) Optimization of electrolyte flow and vanadium ions conversion by utilizing variable porosity electrodes in vanadium redox flow batteries. Chem Phys 529:110577. https:// doi.org/10.1016/j.chemphys.2019.110577

17. Xu Z, Xiao W, Zhang K et al (2020) An advanced integrated electrode with micron- and nano-scale structures for vanadium redox flow battery. J Power Sources 450:227686. https://doi.org/10.1016/ j.jpowsour.2019.227686

18. Aramendia I, Fernandez-Gamiz U, Martinez-San-Vicente A et al (2021) Vanadium redox flow batteries: a review oriented to fluid-dynamic optimization. Energies 14:176. https://doi.org/10.3390/en14010176

19. Prumbohm E, Wehinger GD (2019) Exploring flow characteristics in vanadium redox-flow batteries: optical measurements and CFD simulations. Chem Ing Tech 91:900-906. https://doi.org/10.1002/ cite. 201800164

20. Ke X, Prahl JM, Alexander JID et al (2018) Redox flow batteries with serpentine flow fields: distributions of electrolyte flow reactant penetration into the porous carbon electrodes and effects on performance. J Power Sources 384:295-302. https://doi.org/10.1016/j.jpowsour.2018.03.001

21. Becker $\mathrm{M}(2020)$ Validation of a two-dimensional model for vanadium redox-flow batteries. Schriftenreihe des Energie-Forschungszentrums Niedersachsen (EFZN), v.65. Cuvillier Verlag, Göttingen

22. Kok MD, Jervis R, Tranter TG et al (2019) Mass transfer in fibrous media with varying anisotropy for flow battery electrodes: direct numerical simulations with 3D X-ray computed tomography. Chem Eng Sci 196:104-115. https://doi.org/10.1016/j.ces.2018.10.049

23. Becker M, Bredemeyer N, Tenhumberg N et al (2017) Kinetic studies at carbon felt electrodes for vanadium redox-flow batteries under controlled transfer current density conditions. Electrochim Acta 252:12-24. https://doi.org/10.1016/j.electacta.2017.07.062

24. Moghaddam EM, Foumeny EA, Stankiewicz AI et al (2021) Heat transfer from wall to dense packing structures of spheres, cylinders and Raschig rings. Chem Eng J 407:127994. https://doi.org/10. 1016/j.cej.2020.127994 
25. Gostick JT, Fowler MW, Pritzker MD et al (2006) In-plane and through-plane gas permeability of carbon fiber electrode backing layers. J Power Sources 162:228-238. https://doi.org/10.1016/j. jpowsour.2006.06.096

26. Tjaden B, Brett DJL, Shearing PR (2018) Tortuosity in electrochemical devices: a review of calculation approaches. Int Mater Rev 63:47-67. https://doi.org/10.1080/09506608.2016.1249995

27. AMG TITANIUM ALLOYS \& COATINGS GfE Metalle und Materialien GmbH Chemicals_Vanadium Electrolyte Solution 1.6 M: GfE Article no. 2012 114. Accessed 23 Oct 2020

28. Krishnamurthy D, Johansson EO, Lee JW et al (2011) Computational modeling of microfluidic fuel cells with flowthrough porous electrodes. J Power Sources 196:10019-10031. https://doi.org/10.1016/j.jpowsour.2011.08.024

29. Lisboa KM, Marschewski J, Ebejer N et al (2017) Mass transport enhancement in redox flow batteries with corrugated fluidic networks. J Power Sources 359:322-331. https://doi.org/10.1016/j. jpowsour.2017.05.038

30. Siemens Digital Industries Software (2020) Simcenter STAR$\mathrm{CCM}+$ : User Manual

31. Weltens H, Bressler H, Terres F et al. (1993) Optimisation of catalytic converter gas flow distribution by CFD prediction. In: SAE technical paper series. SAE International400 commonwealth drive, Warrendale, PA, United States. https://doi.org/10.4271/930780

32. Kroner I, Becker M, Turek T (2020) Determination of rate constants and reaction orders of vanadium-ion kinetics on carbon Fiber electrodes. ChemElectroChem 7:4314-4325. https://doi.org/10.1002/ celc. 202001033

33. Graphite Materials \& Systems SGL Carbon GmbH (2019) SIGRACELL* battery felts (*registered trademarks of SGL Carbon SE): Virgin and thermal activiated electrodes made from carbon and graphite felt. Accessed 12 Jan 2021

34. Minke C, Turek T (2018) Materials, system designs and modelling approaches in techno-economic assessment of all-vanadium redox flow batteries - a review. J Power Sources 376:66-81. https://doi. org/10.1016/j.jpowsour.2017.11.058

35. Electrical Power Research Institute (2007) Vanadium Redox Flow Batteries: An in-depth analysis 1014836, Palo Alto, CA (USA)

Publisher's note Springer Nature remains neutral with regard to jurisdictional claims in published maps and institutional affiliations.

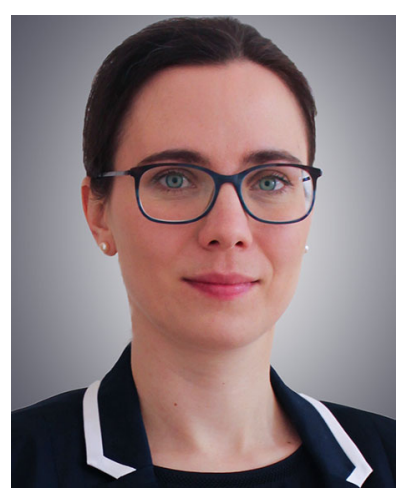

Eva Prumbohm is a $\mathrm{PhD}$ student at the Institute of Chemical and Electrochemical Process Engineering at Clausthal University of Technology. She studied at the master level process engineering at Clausthal University of Technology until 2015 and at the bachelor level mechanical engineering at Technische Universität Braunschweig until 2012. Her research interests cover the flow behaviour of vanadium redox flow batteries and thereby especially flow field designs.

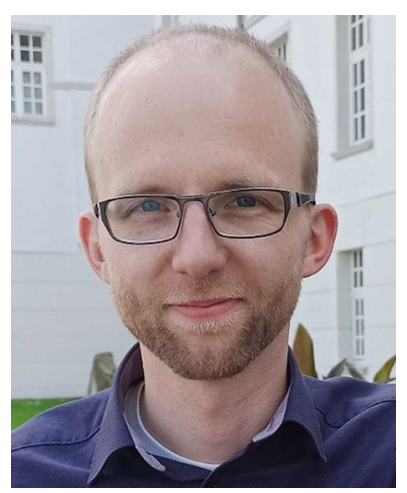

Maik Becker is a postdoc at the Research Center for Energy Storage Technologies at Clausthal University of Technology since 2020. He studied chemical engineering at Clausthal University of Technology, where he received his diploma and his PhD. From 2016 he worked as process engineer for thyssenkrupp Industrial Solutions in Dortmund and returned to Clausthal in 2019. His research aims at the development and cost-sensitive design of new redox-flow battery and water electrolysis systems and processes.

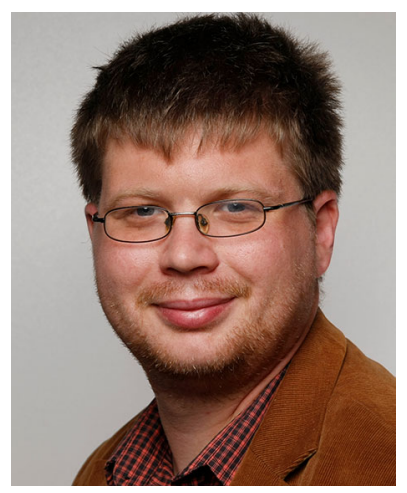

Steffen Flaischlen studied process engineering at Anhalt University of Applied Sciences and Clausthal University of Technology, where he received his master degree in 2018 . He is a scientific assistant in the research group of Gregor D. Wehinger at Clausthal University of Technology. His research focuses on particle-resolved CFD simulations of catalytic fixed bed reactors.

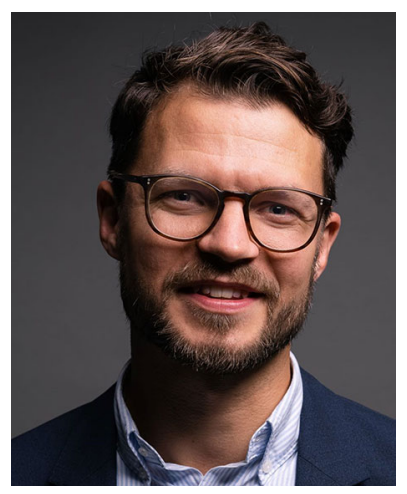

Gregor D. Wehinger is an assistant professor at the Institute of Chemical and Electrochemical Process Engineering at Clausthal University of Technology since 2017. He holds a PhD and diploma from Technische Universität Berlin. During his PhD, he spent a research semester at Brown University, RI, USA. In 2018, he received the Hanns-Hofmann Award from Dechema. 


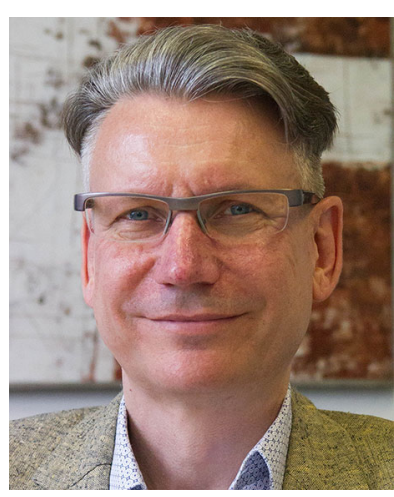

Thomas Turek studied chemical technology and chemical engineering at Dortmund and Karlsruhe University, where he received his doctoral degree in 1992. After a postdoctoral stay at the University of New South Wales in Sydney, Australia, he went back to Karlsruhe University as a group leader and completed his habilitation in the field of catalytic nitrogen oxides abatement. From 2000 to 2004, he worked as process engineer at Bayer Technology Services $\mathrm{GmbH}$ in Leverkusen, before he was appointed full professor at Clausthal University of Technology. His research is targeted at the design of porous catalysts and reactors for chemical and electrochemical processes with the main emphasis on energy transformation and storage. 